\title{
Population, Immigration and Growth in a Romer Endogenous Growth Model
}

\author{
Pedro J. Gutiérrez* \\ University of Valladolid, Spain
}

\begin{abstract}
Endogenous growth theory has not yet consistently incorporated population growth or immigration into its models. As a result, in the present day, there is no universally accepted endogenous growth model explaining the empirical observed relationships between growth, population and immigration. The present paper overcomes this inconvenience by designing a fully specified Romer endogenous growth model, completely microfounded, that incorporates the existence of population growth and immigration and that allows the stylized facts of growth as well as the relationships between growth, population and immigration to be explained. In addition, the proposed model is susceptible to calibration and simulation, and, when applied to the US economy, provides a good fit to the data.

JEL classification: D5, E4, E5.

Keywords: Stochastic General Equilibrium Model; Endogenous Growth; Romer's (1986) Model; Population; Immigration; Immigrant-native complementarity.
\end{abstract}

\section{Introduction}

At least since Malthus (1826), the relationships between population dynamics and economic growth have been widely investigated by economists and social theorists. Over the last few decades and in close connection with the development of the modern theory of endogenous economic growth and the concern over the sustainability of growth, Economics has increased its interest in studying these links, focusing principally on ascertaining the effects of population growth and immigration on human capital accumulation and thus on economic growth ${ }^{1}$. Concerning the links between population and growth, at the empiri-

\footnotetext{
*E-mail address: pedrojos@fae.uva.es (P.J. Gutiérrez). Postal address: Dpto. de Fundamentos del Análisis Económico e Historia e Instituciones Económicas, Facultad de CC.EE. y EE., Universidad de Valladolid, Avda. Valle Esgueva, 6, 47011 Valladolid, SPAIN. Financial support from Spanish Office of Economy and Competitiveness and European FEDER Funds, research project MTM2014-56022-C2-2-P, is gratefully acknowledged. The author also thanks the kind assistance of Alan F. Hynds.

${ }^{1}$ Of course there exists abundant literature analyzing other interesting demographic topics such as aging, fertility, urbanization, etc. However, in this paper we will only consider the macroeconomic effects of population and immigration on growth, but not studies at the family level or discussing sustainability of the social security and fiscal systems.
} 
cal level and as documented among others by Higgings and Williamson (1997), Mason (1997), Bloom and Canning (2001), Kelley and Schmidt (2003), Barro and Sala-i-Martin (2003), Sachs (2008) and Dao (2012), the current consensus is that high population growth exerts a negative effect both on GDP growth and human capital accumulation, this effect being negligible when population growth rates take moderate values. At the theoretical level, however, there is no universally accepted endogenous growth model explaining these empirical findings. Indeed, most endogenous growth models tackling this question conclude that either population growth is one of the principal drivers of per capita income growth -Romer (1990), Grossmand and Helpman (1991), Aghion and Howitt (1992, 2009), Goodfriend and McDermott (1995), Galor and Weil (2000), Hansen and Prescott (2002), Lucas (2009), Acemoglu (2009), Weber (2010)-, or there exists a null (but not negative) effect of the population growth rate on the per-capita output growth rate -Young (1998), Howitt (1999), Barro and Sala-i-Martin (2003). In any case and to our knowledge, there is in the literature no referential model detailing how and why economic growth can, or cannot, be negatively dependent on population growth through the process of human capital accumulation, central to the endogenous growth theory.

This theoretical shortage is also present in the main analysis of the effects of immigration on growth. As recognized among many others by Borjas (1999), Kónya (2009) and Poot and Cochrane (2005), the relationship between immigration and growth is multifaceted and complex, and there remain important and relevant questions to elucidate ${ }^{2}$. The recent studies due to Zak et al (2002), Cipriani (2006) and Ehrlich and Kim (2015) shed some light on these unknowns, but do not completely clarify the nature and significance of the relationships between growth and immigration. In this respect, although Zak et al (2002) and Cipriani (2006) are able to clarify the consequences of immigration on human capital and growth by using an overlapping generation model, they explain these effects on the basis of an exogenous law of human capital accumulation that depends on immigration, departing from the hypothesis of endogenous growth. These authors also provide an endogenous explanation of the decision to migrate, but do not explain how the demand of immigration appears, a shortage answered by Ehrlich and Kim (2015). Indeed, in our opinion, these researchers provide the most satisfactory explanation of the links between immigration, human capital, and growth. More specifically, Ehrlich and Kim (2015) propose a version of a growth model that originates immigration flows by linking them to the growth dynamics of the host economy in a double sense: on the one hand, economic growth gives rise to an immigration demand ${ }^{3}$, which, in turn, affects growth through its effects on the human capital accumulation process. Nevertheless, although Ehrlich and Kim's (2015) model captures the main observed features of the immigration-growth relationships, it does not endogeneizes the human capital accumulation, which indeed is exogenously imposed, therefore moving away from the standard endogenous growth theory.

Delving into this question, the objective of this paper is to incorporate the interesting and realistic ideas in Ehrlich and Kim (2015) concerning immigration into a pure endogenous growth model with population growth $\grave{a}$ la Romer by endogeneizing the human capital accumulation law and the demand of im-

\footnotetext{
${ }^{2}$ See also the references provided by these authors.

${ }^{3}$ On this point, Kónya (2009) finds empirical evidence supporting the existence of this causality effect of growth on immigration.
} 
migrants. In particular, as in Romer $(1986,1990)$, it will be assumed that the growth dynamics is explained by the endogenous human capital accumulation process. In addition, as suggested by Ehrlich and Kim (2015), the demand of immigration will endogenously arise as a consequence of the productive needs of the economy, and will subsequently alter growth through modifications in the human capital accumulation. However, and unlike Ehrlich and Kim (2015) and alternative growth models incorporating population growth, the derived law of human capital accumulation will depend on population growth and immigration, and therefore all the effects of population and immigration on growth will be endogenous in our model. More specifically, our objective is twofold. On the one hand, to provide a theoretical endogenous growth model able to capture the links between population, immigration and growth commented on above. On the other hand, to design a tractable model, susceptible to calibration and simulation, allowing these relationships to be estimated and simulated for different scenarios. Concerning the first goal, we will consistently incorporate all the suggestions proposed by Romer $(1986,1990)$, explaining self-sustained growth on the basis of an endogenously generated law of accumulation of human capital. In addition, we will introduce the realistic idea in Ehrlich and Kim (2015) of an endogenous demand of immigration, on the basis of the empirically documented complementarity in production between immigrants and natives. With respect to our second objective, the proposed Romer model will deliberately be easy to solve, calibrate and simulate, in order to allow the main empirical findings concerning the relationships between immigration and growth to be replicated.

The paper is divided into 7 sections. After this Introduction, Section 2 provides a description of the economy, defines the equilibrium, and states the equivalent social planner's problem. Section 3 discusses the theoretical properties and implications of the AK version of the model, paying special attention to the verification of the stylized facts of growth. The relationships between population, immigration and growth are analyzed in sections 4 and 5, section 6 being devoted to the calibration and simulation of the model for the US economy. Finally, in Section 7, we provide some concluding commentaries.

\section{The Economy}

As commented on in the former section, we will introduce the possibility of population growth and immigration on the basis of a standard Romer's (1986, 1990) model of endogenous growth. More specifically, we will extend the version of the Romer endogenous growth model proposed by Gutiérrez (2015), incorporating as additional features the existence of a growing population and the presence of complementarity in production between immigrants and natives. As in Gutiérrez (2015), we will faithfully follow the suggestions in Romer (1986, 1990). Therefore, it will be considered that there are three types of agents in the economy: households, firms and government.

Concerning firms, and as in Romer (1986), it will be assumed that the production function of each firm incorporates knowledge as an input, that knowledge used by a firm has a positive external effect on the production possibilities of other firms, and that the production functions display constant returns to scale in production factors other than knowledge. Also following Romer's (1986) suggestions, physical capital and knowledge will be used in fixed pro- 
portions in production. In particular, it will be assumed that the number of units of knowledge that combine with one unit of physical capital to produce output is a stochastic variable, an assumption that captures the existence of purely random elements affecting the efficiency of learning by doing and knowledge transmission processes. Concerning labor input, we will assume that there exists a perfect complementarity between immigrant and native labor. This is consistent with the abundant empirical evidence found by Borjas (1983, 1986), Peri (2007), Dustmann et al (2007), D'Amuri et al (2010), Amuedo-Dorantes and De La Rica (2011), Manacorda et al (2012), Ottaviano and Peri (2012) and Dustmann et al (2012), among many others, which supports the existence of a strong complementarity between immigrant and native labor. In this respect, the amount of immigrant labor that combines with one unit of native labor to produce output will be an additional stochastic variable, since, like the complementarity between physical and human capital, it depends on random variables associated to the evolution of learning, ability and knowledge. Jointly with these two complementarity rates, the native population growth rate and the immigrant population/total population ratio will also be considered as stochastic variables, given the uncertain elements affecting fertility and mortality rates and immigration. The stochastic nature of all the aforementioned variables plays a double role. On the one hand, it captures the existence of purely aleatory elements affecting the complementarity rates and the population growth. On the other hand, it allows non-constant rates of growth to be introduced, therefore enabling a better reproduction of the empirical facts. On this point, it is worth noting that the standard statistical procedures to extract the growth trend from a time series, such as the Hodrick-Prescott filter, imply non-constant growth rates; in any case, it would always be possible to eliminate the random elements and to restrict the model to the deterministic case. Concerning the uncertainty scheme, let $\mathcal{S}$ denote the finite set of states of nature that arises from the joint distribution of the three stochastic variables. Let $\mathcal{E}$, $e, e+1, e-1, t(e), f(e)$ and $\pi(e)$ be, respectively, the event tree associated to this uncertainty scheme, a node in the event tree, the nodes immediately subsequent to $e$, the node immediately preceding $e$, the period of time at which the node $e$ happens, the history of nodes leading to node $e$, and the probability of occurrence of $e$. After any node $e$ only a state of nature $s \in \mathcal{S}$ can happen, the subsequent node being denoted by es.

Let $Y_{e}^{i}, K_{e}^{i}, L_{e}^{i}, M_{e}^{i}$ and $H_{e}^{i}$, at node $e$ and for the firm $i$, be respectively production, use of physical capital, use of native labor services, use of immigrant labor services, and use of knowledge/human capital. Let $h_{e}^{j}, j \neq i$, denote the per-capita use of knowledge/human capital by firm $j$ at node $e$. A convenient way to capture the abovementioned features is through the production function

$$
\begin{gathered}
Y_{e}^{i}=F\left(K_{e}^{i}, L_{e}^{i}, M_{e}^{i}, h_{e}^{1}, h_{e}^{2}, \ldots, H_{e}^{i}, \ldots, h_{e}^{J}\right)= \\
A\left[\min \left\{a_{e} K_{e}^{i}, H_{e}^{i}\right\}\right]^{\alpha}\left[\min \left\{b_{e} L_{e}^{i}, M_{e}^{i}\right\}\right]^{1-\alpha}\left(\prod_{j \neq i} h_{e}^{j}\right)^{\rho}, \\
i=1,2, \ldots, J,
\end{gathered}
$$

where $A$ is the total factor productivity; $a_{e}$ is the number of units of knowledge that combine with one unit of physical capital to produce output; $b_{e}$ is the amount of immigrant labor that combines with one unit of native labor to 
produce output; $\alpha,(1-\alpha)$ and $\rho$ are the input elasticities; $i=1,2, \ldots, J$ is the superscript denoting the firm; $J$ denotes the total number of firms; and the term $\left(\prod_{j \neq i} h_{t}^{j}\right)^{\rho}$ captures the external effects of the (per-capita) knowledge used by the other firms on firm $i$ 's production.

Let us now consider the household's problems. At node $e$, let $N_{e}$ and $Q_{e}$ be, respectively, the number of natives and immigrants. Therefore, $P_{e}=N_{e}+Q_{e}$ is the total population at node $e$. Let $p_{e}$ be the growth rate of the total population at node $e$. Under the assumption of complete markets and the total removal of individual uncertainties, the household's problem for the native workers is, in per-capita terms,

$$
\max _{C_{e}^{n}, k_{e}^{n}, h_{e}^{n}, l_{e}^{n}} \sum_{e \in \mathcal{E}} \beta_{n}^{t(e)} \pi_{n}(e) U^{n}\left(C_{e}^{n}\right)
$$

$$
\begin{gathered}
\text { s.t. } C_{e}^{n}+\left[k_{e+1}^{n}\left(1+p_{e}\right)-k_{e}^{n}\left(1-\delta_{k}\right)\right]+\left[h_{e+1}^{n}\left(1+p_{e}\right)-h_{e}^{n}\left(1-\delta_{h}\right)\right]+T_{e}^{n} \leq \\
w_{e} l_{e}^{n}+r_{e} k_{e}^{n}+d_{e} h_{e}^{n}, \\
C_{e}^{n} \geq 0, \\
0 \leq l_{e}^{n} \leq \bar{l}_{e}, \\
e \in \mathcal{E}
\end{gathered}
$$

$k_{0}^{n}, h_{0}^{n} \quad$ historically given,

where $\beta_{n} \in(0,1), \pi_{n}, U^{n}, C^{n}, k^{n}, h^{n}, T^{n}, l^{n}$, and $\bar{l}_{e}$ are, respectively, the discount factor, the subjective beliefs, the instantaneous utility function, the consumption of good, the participation in physical capital, the household level of knowledge, the taxes paid to government, the labor supply, and the time endowment for native workers. Regarding prices and depreciation rates, $w$, $r, d, \delta_{K} \in(0,1)$, and $\delta_{h} \in(0,1)$ are, respectively, the labor input price for native workers, the physical capital input price, the knowledge input price, the depreciation rate of physical capital, and the depreciation rate of knowledge.

Analogously, the household's problem for the immigrant workers is, in per capita terms,

$$
\begin{gathered}
\max _{C_{e}^{q}, k_{e}^{q}, h_{e}^{q}, m_{e}^{q}} \sum_{e \in \mathcal{E}} \beta_{q}^{t(e)} \pi_{q}(e) U^{q}\left(C_{e}^{q}\right) \\
\text { s.t. } \quad C_{e}^{q}+\left[k_{e+1}^{q}\left(1+p_{e}\right)-k_{e}^{q}\left(1-\delta_{k}\right)\right]+\left[h_{e+1}^{q}\left(1+p_{e}\right)-h_{e}^{q}\left(1-\delta_{h}\right)\right]+T_{e}^{q} \leq \\
g_{e} m_{e}^{q}+r_{e} k_{e}^{q}+d_{e} h_{e}^{q}, \\
C_{e}^{q} \geq 0, \\
0 \leq m_{e}^{q} \leq \bar{m}_{e}, \\
e \in \mathcal{E}
\end{gathered}
$$

$k_{0}^{q}, h_{0}^{q} \quad$ historically given,

where $\beta_{q} \in(0,1), \pi_{q}, U^{q}, C^{q}, k^{q}, h^{q}, T^{q}, m^{q}$, and $\bar{m}_{e}$ are, respectively, the discount factor, the subjective beliefs, the instantaneous utility function, the consumption of good, the participation in physical capital, the household level of knowledge, the taxes paid to government, the labor supply, and the time endowment for immigrant workers. Regarding prices, $g$ is the labor input price for immigrant workers, and $r, d, \delta_{K} \in(0,1)$, and $\delta_{h} \in(0,1)$ are the above defined. 
As is obvious, our household's problems are the standard ones in a competitive general equilibrium model. For each problem, the budget constraint simply says that, at each node, the household's wealth, given by the remuneration to the labor, physical capital and knowledge used in production, is used to acquire consumption good, to increase its participation in the physical capital input, to accumulate knowledge input, and to pay taxes. It is then assumed, as in Romer (1986), that there is a trade-off between consumption today and knowledge that can be used to increase consumption tomorrow. The only difference between native and immigrant workers is then the type of supplied labor. Indeed, both immigrants and native workers can accumulate physical as well as human capital, which are homogeneous production inputs. However, they offer distinct types of labor, namely $l$ and $m$, that are consequently differently remunerated at prices $w$ and $g$, respectively. The proposed model therefore assumes the existence of a segmented labor market, which, when $w>g$, can be envisaged as the result of the coexistence of two types of workers, namely high-skilled-remunerated native workers and low-skilled-remunerated immigrant workers. Note also that the time endowment for immigrant workers is given in per-capita terms, and that, accordingly, it depends on the total number of immigrants in the economy, which, in turn, hinges on both the immigration policy in the destination country and the migrant supply of out-migration countries. In this respect, following the standard theories of migration proposed by Borjas $(1990,1999)$, it will be assumed that the immigrant labor supply is perfectly elastic at the wage $g$, since this wage is higher than those existing in the outmigration countries ${ }^{4}$. This implies that the number of immigrants is totally determined by the demand of immigrants and the immigration policy of destination countries, two theoretical results consistent with the empirical evidence. In this respect, the clearest sign of a perfectly elastic supply of immigrant labor and the effective limitation of the number of immigrants by the complementarity between native and immigrant workers is the existence of substantial non-legal immigration in most of the destination economies.

Finally, Government establishes the immigration policy, collects lump-sum taxes from the agents and internalizes the externalities in production through optimal taxes and subsidies to firms. Under this kind of government intervention, the competitive general equilibrium -defined through the usual conditions of utility maximizing consumers, profit maximizing firms, zero net profits and market clearing-, can be formulated as the solution of a social planner's problem, an idea pointed out by Romer in his reference paper. As shown in appendix A this happens for our economy, whose general equilibrium is equivalent to the following social planner's problem:

${ }^{4}$ See also Zak et al (2002) and Cipriani (2006). 
Definition (Equivalent Social Planner's Problem). The per-capita equilibrium sequences of consumption, human capital and immigrant labor $\left\{C_{e}\right\},\left\{h_{e}\right\}$ and $\left\{m_{e}\right\}$ in the Long-Run Competitive General Equilibrium are given by the solution of the social planner's problem

$$
\begin{gathered}
\max _{C_{e}, h_{e}, m_{e}} \sum_{e \in \mathcal{E}} \beta^{t(e)} \pi(e) U\left(C_{e}\right) \\
\text { s.t. } C_{e}+h_{e+1}\left(1+p_{e}\right)\left(1+\frac{1}{a_{e}}\right) \leq A h_{e}^{\alpha+\rho} m_{e}^{1-\alpha}+h_{e}\left[1-\delta_{h}+\frac{1}{a_{e}}\left(1-\delta_{k}\right)\right], \\
C_{e} \geq 0, \\
0 \leq m_{e} \leq \bar{m}_{e}, \\
e \in \mathcal{E}, \\
h_{0} \quad \text { historically given. }
\end{gathered}
$$

It is worth noting that this version of Romer's endogenous growth model not only constitutes a rigorous and manageable microfoundation of Romer's (1986, 1990) endogenous growth model, but also explicitly and consistently introduces significant observed features of actual economies concerning population, immigration and government intervention. On the one hand and as commented on in the introductory section, total population usually grows at positive rates, and the empirical evidence suggests that immigrant and native workers are mostly complementary inputs in production, two features incorporated in our model. Additionally, this is not the only relationship between native and immigrant labor that the model contemplates. Since there is a unique immigrant labor segment, characterized by a unique wage $g$, any new immigrant is a perfect substitute for any other former immigrant, a substitutional pattern also observed in real economies. The same happens in the native labor market, and then a substitutive relationship between immigrant cohorts and natives as time passes also exists in the model. Indeed, since there is a unique native labor market with a unique equilibrium wage $w$, first and subsequent generations of migrants are perfect substitutes for native workers, given that the former were born in the destination economy and therefore considered as natives. This is consistent with the existence for immigrant families of a naturalization process, along which they acquire similar social, educational, economic and working habits to natives, and that, according to the empirical literature ${ }^{5}$ takes around one generation. On the other hand and concerning government intervention, it is clear that public subsidies to R\&D firm activities and to professional training, patents, licences and copyrights, pursue the internalization of the knowledge externalities, an aspect captured by our model through the variable $S$, the subsidy/tax to the knowledge input. In addition, when the production sector is envisaged as an aggregate agent producing knowledge as well as commodities, the public financial support of research and education can be assimilated to the lump-sum subsidy to profits $V$ introduced in the model.

As we will see in the next section, the proposed model generates an endogenous demand of immigration, and will allow the two-sense links between

\footnotetext{
${ }^{5}$ See for instance Sobotka (2008), Milewski (2007), Tønnessen (2014), Public Policy Institute of California (2002) and the references there provided.
} 
growth, human capital accumulation and immigration to be analyzed inside a pure endogenous growth model, both from the theoretical and empirical perspectives. Indeed, under appropriate specifications, this model is susceptible to exact solution, calibration and simulation, something that constitutes a clear advantage with respect to other models used to study the relationships between immigration and growth. This will be done in the following sections for the particular case in which $\alpha+\rho=1$, that leads to a very interesting AK model.

\section{Population, Immigration and Growth in a Romer- AK Endogenous Growth Model}

When in the social planner's problem (3) the values of the elasticities $\alpha$ and $\rho$ are such that $\alpha+\rho=1$, then

$$
y_{e}=A h_{e}^{\alpha+\rho} m_{e}^{1-\alpha}=A h_{e} m_{e}^{1-\alpha}=A a_{e} k_{e} m_{e}^{1-\alpha},
$$

where $y_{e}$ is the per capita total output. The resulting Romer's (1986) model is therefore a particular version of the AK model, characterized by the presence of constant returns to physical capital.

Without any doubt, AK models are the most studied and discussed endogenous growth models in the literature. From the theoretical perspective, there exists a wide variety of models justifying constant returns to physical capital -such as those by Lucas (1988), Barro (1990), Jones and Manuelli (1990) and Rebelo (1991)-, as well as numerous studies on the versatility of AK models -for instance in considering stochastic technology and labor input shocks, as in Binder and Pesaran (1999); nonlinear tax structures, as in Yamarik (2001); different long-term growth rates, as in Krawczyk and Shimomura (2003); or the different effects of monetary policy, as in Chen and Guo (2008). The empirical analyses on the validity of AK models are also abundant. On this point, suffice it to quote the studies by McGrattan (1998), Li (2002), Kim (2003) or Romero -Ávila (2009, 2013).

The above comments on the theoretical relevance and proper empirical behavior of the AK models, jointly with the richness inherent to a Romer (1986) model that in addition incorporates population growth and immigration, constitute arguments supporting the interest of studying and discussing the AK version of Romer's (1986) model proposed in this paper. We will begin by solving the social planner's problem (3), later discussing its theoretical properties. In this respect, we refer the reader to the results in Gutiérrez (2015), since our social planner's problem is mathematically equivalent to the analyzed in that paper $^{6}$.

More specifically, defining $\delta=\delta_{h}-\frac{1-\delta_{k}}{a}$, if we assume that the instantaneous utility function is given by the expressions

$$
U\left(C_{e}\right)=\ln \left(C_{e}\right)
$$

and, alternatively,

$$
U\left(C_{e}\right)=\frac{C_{e}^{1-\sigma}-1}{1-\sigma}, \quad(\sigma>0) \wedge(\sigma \neq 1),
$$

${ }^{6}$ Indeed, by substituting $\left(1+\frac{1}{a+\theta_{e}}\right)$ in Gutiérrez (2015) for $\left(1+\frac{1}{a_{e}}\right)\left(1+p_{e}\right)$, we arrive to problem (3) 
(where $\sigma$ is the intertemporal elasticity of substitution in consumption), the solution policy and control functions are

$$
\begin{gathered}
h_{e+1}=h_{e}\left[\frac{\beta\left(A \bar{m}_{e}^{1-\alpha}+1-\delta\right)}{\left(1+\frac{1}{a_{e}}\right)\left(1+p_{e}\right)}\right]^{\frac{1}{\sigma}}, \\
C_{e}=h_{e}\left\{A \bar{m}_{e}^{1-\alpha}+1-\delta-\left[\left(1+\frac{1}{a_{e}}\right)\left(1+p_{e}\right)\right]^{\frac{\sigma-1}{\sigma}}\left[\beta\left(A \bar{m}_{e}^{1-\alpha}+1-\delta\right)\right]^{\frac{1}{\sigma}}\right\}
\end{gathered}
$$

when

$$
U\left(C_{e}\right)=\frac{C_{e}^{1-\sigma}-1}{1-\sigma}, \quad(\sigma>0) \wedge(\sigma \neq 1),
$$

and

$$
\begin{gathered}
h_{e+1}=h_{e}\left[\frac{\beta\left(A \bar{m}_{e}^{1-\alpha}+1-\delta\right)}{\left(1+\frac{1}{a_{e}}\right)\left(1+p_{e}\right)}\right], \\
C_{e}=h_{e}\left[A \bar{m}_{e}^{1-\alpha}+1-\delta\right][1-\beta]
\end{gathered}
$$

when $U\left(C_{e}\right)=\ln \left(C_{e}\right)$. From these expressions, denoting the per-capita growth rates of human capital, consumption, output and physical capital by $\psi_{h}, \psi_{C}$, $\psi_{y}$, and $\psi_{k}$, respectively, it is straightforward that when

$$
\begin{gathered}
U\left(C_{e}\right)=\frac{C_{e}^{1-\sigma}-1}{1-\sigma}, \quad(\sigma>0) \wedge(\sigma \neq 1), \\
\psi_{h}=\psi_{C}=\psi_{y}=\psi_{k}=\left[\frac{\beta\left(A \bar{m}_{e}^{1-\alpha}+1-\delta\right)}{\left(1+\frac{1}{a_{e}}\right)\left(1+p_{e}\right)}\right]^{\frac{1}{\sigma}}-1,
\end{gathered}
$$

and when $U\left(C_{e}\right)=\ln \left(C_{e}\right)$, the growth rates are

$$
\psi_{h}=\psi_{C}=\psi_{y}=\psi_{k}=\left[\frac{\beta\left(A \bar{m}_{e}^{1-\alpha}+1-\delta\right)}{\left(1+\frac{1}{a_{e}}\right)\left(1+p_{e}\right)}\right]-1
$$

Applying the arguments in Gutiérrez (2015), it is possible to conclude that the following stylized facts of growth ${ }^{7}$ are verified in our proposed model ${ }^{8}$ :

- The real per-capita output grows at a steady trend rate.

- The stock of per-worker physical capital grows at a steady trend rate.

- The ratio physical capital/output is steady across time.

- Capital and labor's shares in total income are steady across time.

- The rate of return of physical capital is steady across time.

- The rate of growth of output per-capita varies greatly across economies, suggesting the existence of poverty traps and convergence clubs.

\footnotetext{
${ }^{7}$ See Kaldor (1957), Barro and Sala-i-Martin (2003), Cooley and Prescott (1995), Durlauf et al (2005), and Azariadis and Stachurski (2005), and the references given in the introductory section.

${ }^{8}$ See section 4 and the mean and standard deviation of the relevant variables and ratios
} 
- There exists a positive correlation between the rate of growth and the economy level of scientific and technical knowledge.

- High population growth rates are negatively correlated with per-capita output growth rates.

The explanation of the coexistence of very different output growth rates across economies, of the positive correlation between knowledge and growth, and of the negative correlation between population growth and GDP growth, come directly from the analysis of the growth rate expression. In effect, in our model, where the growth rates take the expressions specified in (4) and (5), differences in the evolution of the variables $a_{e}, \bar{m}_{e}$ and $p_{e}$ across economies can explain why countries can have distinct growth rates, even when the economies present the same technology and preferences ${ }^{9}$. In addition, following the arguments in Gutiérrez (2015), it is straightforward to show that the existence of threshold values for the technological parameter $a_{e}$ and the population growth rate $p_{e}$ become relevant in explaining the empirically observed poverty traps and convergence clubs, including their intricate behavior and their complex dependence on both population growth and technological aspects ${ }^{10}$.

\subsection{Population and Growth}

Let us focus on the relationships between the per-capita output growth rate and the population growth rate. We will begin by mathematically characterizing the properties of the growth rate expressions with respect to $p_{e}$. When $U\left(C_{e}\right)=$ $\ln \left(C_{e}\right)$ and

$$
\psi_{h}=\psi_{C}=\psi_{y}=\psi_{k}=\left[\frac{\beta\left(A \bar{m}_{e}^{1-\alpha}+1-\delta\right)}{\left(1+\frac{1}{a_{e}}\right)\left(1+p_{e}\right)}\right]-1
$$

the only meaningful range of values occurs when

$$
\frac{\beta\left(A \bar{m}_{e}^{1-\alpha}+1-\delta\right)}{1+\frac{1}{a_{e}}}>1,
$$

since, on the contrary, per-capita output growth rates would always be negative for any positive population growth rate. Indeed, this inequality implies the possibility of positive as well negative growth rates, as observed in actual economies. In this case, it is straightforward to conclude that

$$
\begin{gathered}
\frac{\partial \psi_{h}}{\partial\left(p_{e}\right)}=-\frac{\left(\psi_{h}+1\right)}{\left(1+p_{e}\right)}<0, \\
\frac{\partial^{2} \psi_{h}}{\partial\left(p_{e}\right)^{2}}=2 \frac{\left(\psi_{h}+1\right)}{\left(1+p_{e}\right)^{2}}>0
\end{gathered}
$$

\footnotetext{
${ }^{9}$ This concern has been present since the pioneer works by Romer (1986) and Lucas (1988). ${ }^{10}$ On this point, the interested reader can consult Nelson (1956), Becker et al (1990), Azariadis and Stachurski (2005) and the more recent papers by Rey and Deisting (2012), Moav and Neeman (2012), Raffin (2012), Accinelli and Carrera (2012), Bond, Iwasa and Nishimura (2013), Brito, Costa and Dixon (2013), Barrett and Carter (2013), Camacho, Saglam and Turan (2013), Galvao, Montes-Rojas and Olmo (2013), Sattinger (2013), Kraay and McKenzie (2014), and Alcantar-Toledo and Venieris (2014), among others.
} 


$$
\begin{gathered}
\lim _{p_{e} \rightarrow \infty} \psi_{h}=-1, \\
\left.\psi_{h}\right|_{p_{e}=0}=\left[\frac{\beta\left(A \bar{m}_{e}^{1-\alpha}+1-\delta\right)}{1+\frac{1}{a_{e}}}\right]-1, \\
\psi_{h}=0 \Leftrightarrow p_{e}=\overline{p_{e}}=\frac{\beta\left(A \bar{m}_{e}^{1-\alpha}+1-\delta\right)}{1+\frac{1}{a_{e}}}-1>0 .
\end{gathered}
$$

The graph of $\psi_{h}\left(p_{e}\right)$ is that in figure 1, which must be interpreted in the light of the Romer endogenous growth model which founds our extended model. Indeed, when native and immigrant populations are constant, our model reduces to a pure version of the original Romer (1986) model. Therefore,

$$
\left.\psi_{h}\right|_{p_{e}=0}=\left[\frac{\beta\left(A \bar{m}_{e}^{1-\alpha}+1-\delta\right)}{1+\frac{1}{a_{e}}}\right]-1
$$

represents the endogenous growth rate in the standard Romer (1986) model, in which endogenous growth exclusively appears due to externalities associated with human capital. The slope $\frac{\partial \psi_{h}}{\partial\left(p_{e}\right)}<0$ captures the ceteris-paribus negative effect of population growth on the GDP growth rate. When the population growth rate is the sole changing variable, i.e. when the per-capita time endowment for immigrant workers $\bar{m}_{e}$ remains constant, the per-capita production function becomes

$$
y_{e}=A h_{e} \bar{m}^{1-\alpha},
$$

and then per-capita output only increases due to the accumulation of per-capita human capital $h_{e}$. This increase in human capital $h$ attains its maximum when population is constant: In Romer's (1986) model, per-capita human capital exclusively increases due to its external effects, independent of population size; then, when the population grows, this current increase in $h$ and $y$ must be distributed among a subsequent higher population, and consequently, the percapita output growth rate negatively depends on the population growth rate. Additionally, given this negative dependence, when the population growth rate increases, the output growth rate reaches a point in which the negative effect associated to the population growth rate annuls, and afterwards surpasses, the increase in per-capita output caused by human capital accumulation. With our expressions, these empirically observed phenomena happen when the population growth rate reaches and exceeds

$$
\overline{p_{e}}=\frac{\beta\left(A \bar{m}_{e}^{1-\alpha}+1-\delta\right)}{1+\frac{1}{a_{e}}}-1 .
$$

This theoretical property is therefore consistent with the empirical evidence of the negative effect of a high population growth both on GDP growth and human capital accumulation. In addition, since $\frac{\partial \psi_{h}}{\partial\left(p_{e}\right)}=-\frac{\psi_{h}+1}{1+p_{e}} \approx-\left(\psi_{h}-\right.$ $\left.p_{e}\right)$, this effect is negligible when the output and population growth rates take moderate values, in concordance with the observed data.

All these analyses remain valid when

$$
U\left(C_{e}\right)=\frac{C_{e}^{1-\sigma}-1}{1-\sigma}, \quad(\sigma>0) \wedge(\sigma \neq 1) .
$$


Figure 1: Growth rate, $U\left(C_{e}\right)=\ln \left(C_{e}\right)$.

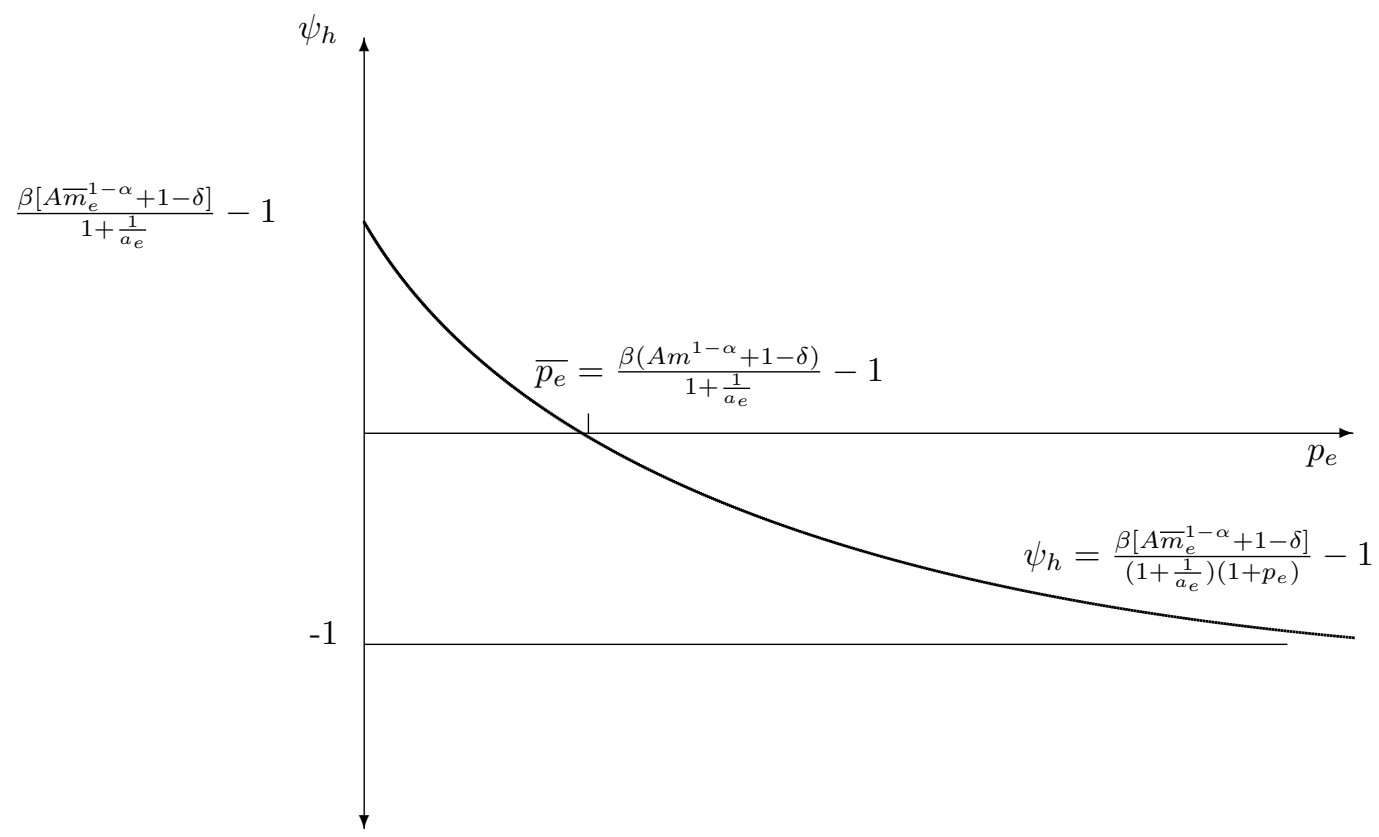

In this case, for the same reasons as in the former, the only meaningful range of values occurs when

$$
\frac{\beta\left(A \bar{m}_{e}^{1-\alpha}+1-\delta\right)}{1+\frac{1}{a_{e}}}>1 .
$$

In this case,

$$
\begin{gathered}
\frac{\partial \psi_{h}}{\partial\left(p_{e}\right)}=-\frac{\left(\psi_{h}+1\right)}{\sigma\left(1+p_{e}\right)}<0, \\
\frac{\partial^{2} \psi_{h}}{\partial\left(p_{e}\right)^{2}}=\frac{(1+\sigma)}{\sigma^{2}} \frac{\left(\psi_{h}+1\right)}{\left(1+p_{e}\right)^{2}}>0, \\
\lim _{p_{e} \rightarrow \infty} \psi_{h}=-1, \\
\left.\psi_{h}\right|_{p_{e}=0}=\left[\frac{\beta\left(A \bar{m}_{e}^{1-\alpha}+1-\delta\right)}{\left(1+\frac{1}{a_{e}}\right)}\right]^{\frac{1}{\sigma}}-1, \\
\psi_{h}=0 \Leftrightarrow p_{e}=\bar{p}_{e}=\frac{\beta\left(A \bar{m}_{e}^{1-\alpha}+1-\delta\right)}{1+\frac{1}{a_{e}}}-1>0,
\end{gathered}
$$

and all the above mentioned properties hold. The graph of $\psi_{h}\left(p_{e}\right)$ in this case is that in figure 2 . 
Figure 2: Growth rate, $U\left(C_{e}\right)=\frac{C_{e}^{1-\sigma}-1}{1-\sigma}$.

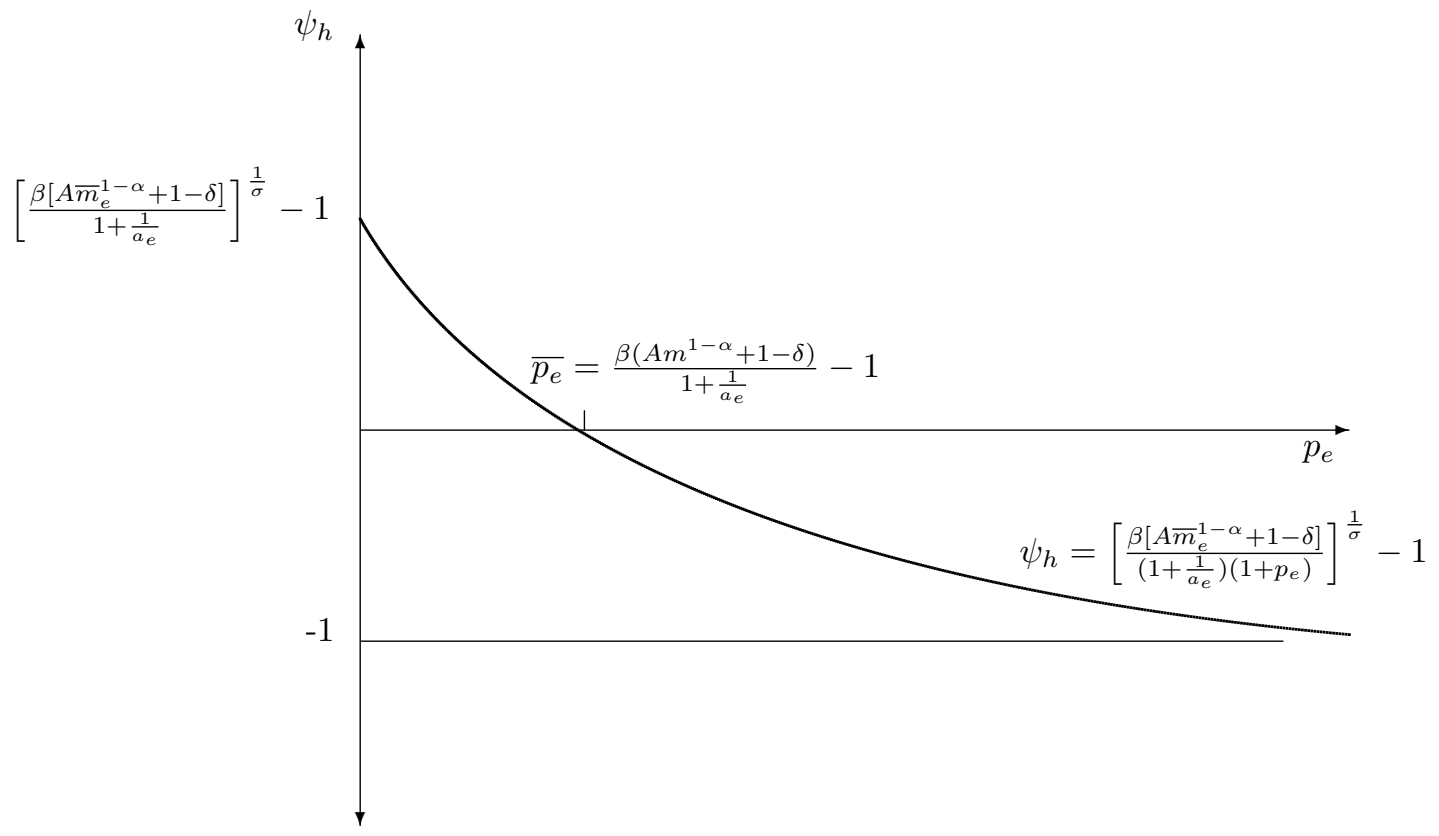

\subsection{Immigration and Growth}

Through the variables $\bar{m}_{e}$ and $p_{e}$, the proposed model allows the relationships between immigration and growth to be evaluated. These two variables are linked, since a modification in the number of immigrants $Q_{e}$ affects both the per-capita time endowment of immigrant labor for the economy $\bar{m}_{e}$ and the total population growth rate $p_{e}$. The dynamics of the model with respect to growth is therefore defined by a set of three equations, the first two capturing the dependence between $\bar{m}_{e}$ and $p_{e}$ and the third showing the associated per-capita GDP growth rate. As shown in appendix B, denoting the individual endowment of time (equal for immigrants and natives) by $\bar{h}$, when the immigration policy always ensures $b_{e} \bar{l}_{e}=\bar{m}_{e}$, i.e., always allows the number of immigrants $Q_{e}$ to adjust to the number of native workers in order to fulfill the productive requirements of perfect complementarity between native and immigrant labor inputs, the behavior of the economy is described by the system of equations

$$
\left\{\begin{array}{l}
p_{e}=n_{e}+\frac{Q_{e}}{P_{e}}\left(\frac{b_{e}-b_{e-1}}{b_{e}-1}\right) \\
\frac{Q_{e+1}}{P_{e+1}}=\frac{Q_{e}}{P_{e}}+\frac{Q_{e}}{P_{e}}\left[\frac{\left(\frac{b_{e}-b_{e-1}}{b_{e}-1}\right)\left(1-\frac{Q_{e}}{P_{e}}\right)}{1+p_{e}}\right] \\
\psi_{e}=\left[\frac{\beta\left[A\left(\frac{\bar{h} Q_{e}}{P_{e}}\right)^{1-\alpha}+1-\delta\right]}{\left(1+\frac{1}{a_{e}}\right)\left(1+p_{e}\right)}\right]-1 \\
\psi_{e}=\left[\frac{\beta\left[A\left(\frac{\bar{h} Q_{e}}{P_{e}}\right)^{1-\alpha}+1-\delta\right]}{\left(1+\frac{1}{a_{e}}\right)\left(1+p_{e}\right)}\right]^{\frac{1}{\sigma}}-1
\end{array}\right.
$$


when $U\left(C_{e}\right)=\ln \left(C_{e}\right)$ and $U\left(C_{e}\right)=\frac{C_{e}^{1-\sigma}-1}{1-\sigma}$ (equation (8) or $\left(8^{\prime}\right)$, respectively).

The growth rate expressions $(8)$ and $\left(8^{\prime}\right)$ allow some interesting conclusions on the relationships between immigration and technological change to be obtained. Since $\bar{m}_{e}=b_{e} \bar{l}_{e}$ and $\bar{l}_{e}=\frac{\bar{h} N_{e}}{P_{e}}$, the per-capita production function can be written

$$
y_{e}=A h_{e} \bar{m}^{1-\alpha}=A h_{e} b_{e} \frac{\bar{h} N_{e}}{P_{e}} .
$$

Two possible technological improvements are possible in the light of this formulation: one associated to increases in the amount of immigrant labor that combines with one unit of native labor $b_{e}$; the other being a consequence of a higher value of the parameter $A$. As we will see, the first always increases the dependence on the immigrant population, only the second opening the possibility of a higher output growth rate and a lower number of immigrants.

To see this, let us consider expression $(8)^{11}$ and the equality

$$
\bar{m}_{e}=\frac{\bar{h} Q_{e}}{P_{e}}=b_{e} \bar{l}_{e}=b_{e} \frac{\bar{h} N_{e}}{P_{e}},
$$

according to which the output growth rate is

$$
\psi_{e}=\left[\frac{\beta\left[A\left(\frac{\bar{h} Q_{e}}{P_{e}}\right)^{1-\alpha}+1-\delta\right]}{\left(1+\frac{1}{a_{e}}\right)\left(1+p_{e}\right)}\right]-1=\left[\frac{\beta\left[A\left(\frac{\bar{h} b_{e} N_{e}}{P_{e}}\right)^{1-\alpha}+1-\delta\right]}{\left(1+\frac{1}{a_{e}}\right)\left(1+p_{e}\right)}\right]-1 .
$$

Taking the derivative $\frac{\partial \psi_{e}}{\partial b_{e}}$, we get

$$
\frac{\partial \psi_{e}}{\partial b_{e}}=\frac{\beta A\left(\bar{h} \frac{N_{e}}{P_{e}}\right)^{1-\alpha}}{\left(a+\frac{1}{a}\right)\left(1+p_{e}\right)}(1-\alpha) b_{e}^{-\alpha}>0,
$$

concluding the existence of a positive dependence of the per-capita output growth rate on the complementarity parameter $b_{e}$.

Since $\frac{\bar{h} Q_{e}}{P_{e}}=b_{e} \frac{\bar{h} N_{e}}{P_{e}}$, then

$$
\frac{\partial\left(\frac{Q_{e}}{P_{e}}\right)}{\partial b_{e}}=\frac{N_{e}}{P_{e}}>0
$$

and therefore this technological improvement is conditional to an increase in the percentage of immigrant population $\frac{Q}{P}$. This is a logical consequence from the economic point of view. Indeed, when the technological improvement turns into a higher value of the parameter $b$-i.e. increases from $b$ to $b^{\prime}-$, this means that a native worker is able to be complemented by $b$ immigrant workers and to obtain the same output as before, and there still remains time and/or capability to be complemented by $b^{\prime}-b$ additional units of immigrant work to obtain more output. In this case, the economy needs additional immigrant workers, so, under an optimal immigration policy, the percentage of immigrant population increases.

On the other hand, a higher value for $A$ opens the possibility of having, simultaneously, an increase in the output growth rate and a decrease in the percentage of immigrant population. Mathematically, since

$$
d \psi_{e}=\frac{\partial \psi_{e}}{\partial A} d A+\frac{\partial \psi_{e}}{\partial b_{e}} d b_{e},
$$

\footnotetext{
${ }^{11}$ Similar reasonings can be applied for expression $\left(8^{\prime}\right)$.
} 


$$
\frac{\partial \psi_{e}}{\partial A}=\frac{\beta\left(\frac{\bar{h} b_{e} N_{e}}{P_{e}}\right)^{1-\alpha}}{\left(1+\frac{1}{a_{e}}\right)\left(1+p_{e}\right)}, \quad \frac{\partial \psi_{e}}{\partial b_{e}}=\frac{\beta A\left(\bar{h} \frac{N_{e}}{P_{e}}\right)^{1-\alpha}}{\left(a+\frac{1}{a}\right)\left(1+p_{e}\right)}(1-\alpha) b_{e}^{-\alpha},
$$

it is straightforward to conclude that when $d A>0, d b_{e}<0$, and $\left|\left(\frac{d b_{e}}{b_{e}}\right)\right|<$ $\frac{1}{1-\alpha} \frac{d A}{A}$, then there exists an increase in the output growth rate, $d \psi_{e}>0$, and a simultaneous decrease in the percentage of immigrant population. In this case and conversely to the first, a higher growth rate is possible without the requirement of additional immigrant workers.

As shown above, the system of equations (6)-(8)(8') describes the dynamics of the model. In this respect, since $b_{e}$ is a stochastic variable, the evolution of the per-capita GDP growth rate under the optimal immigration policy is complex, and can only be evaluated by simulating the model. The interested reader can find a brief theoretical analysis of the dynamic complexity intrinsic to the model in appendix B.

\section{Calibration and simulation of the model for the US Economy}

As commented on before, one of the virtues of the model is the possibility it opens for calibration and simulation. Through equations (6)-(8)(8') and after calibrating the model and characterizing the stochastic variables $a_{e}, b_{e}$ and $p_{e}$, the theoretical behavior of the per-capita GDP growth rate can be simulated and compared to that observed for the economy. Obviously, this exercise constitutes an analysis of the validity of the model, since it determines the degree to which the proposed model explains the empirical data on growth, population and immigration. Depending on the purpose of the analysis and the number of considered stochastic variables, several alternatives are possible. In this respect, the specificity of this model derives from the assumption of the complementarity in production between native and immigrant workers, and given that our interest lies in describing the effects of population and immigration on the per-capita GDP growth rate due to this hypothesis, we will consider $b_{e}, n_{e}$ and $\bar{m}_{e}$ as the unique stochastic variables ${ }^{12}$. Along the next section we will calibrate and simulate this endogenous growth model for the US economy, carrying out separate analyses to study the effects on GDP growth of population and immigration.

Previously to the simulation of the model, it is necessary to calibrate it. This will be done by applying the usual methods and procedures, as is logical taking into account the peculiarities of the model. In order to avoid the distortions caused by the financial crisis suffered by the US and initiated in 2009, the considered sample will go from 1964:1 to 2009:4. Assuming that $b_{e}, n_{e}$ and $\frac{Q_{e}}{P_{e}}$ are the unique stochastic variables, the solution of the model is that given by the system of equations (6)-(8)/( $\left.8^{\prime}\right)$ when $a_{e}=a$. According to these equations and assuming normality for the stochastic variables, the parameters to calibrate are $n, \frac{Q}{P}, \alpha, b, \beta, A, \bar{h}, a, \delta$ and $\sigma$, where $n, \frac{Q}{P}$, and $b$ are the means of the normal distributions characterizing $n_{e}, \frac{Q_{e}}{P_{e}}$ and $b_{e}$. Concerning the native population

\footnotetext{
${ }^{12}$ For alternative assumptions see Gutiérrez (2015), who makes an abstraction of population and immigration variables and focuses on the consequences of the complementarity in production between physical and human capital on growth, considering $a_{e}$ as the sole stochastic variable.
} 
growth rate $n$, the percentage of immigrant population $\frac{Q}{P}$, and the labor's share in total output $1-\alpha=\frac{w L}{Y}$, we will consider the mean values provided by the US Census Bureau for the sample. The values of the subjective discount factor $\beta$ and of the intertemporal elasticity of substitution in consumption $\sigma$ will be those provided by Evans and Sezer (2004). The calibration of $b$ will be based on the data of aggregate employment: since the total per-capita employment is the aggregation of the native and immigrant per-capita employment, and along the balanced path of growth it coincides with the individual time endowment

$$
\bar{h}=\bar{l}_{e}+\bar{m}_{e}=\bar{l}_{e}+b_{e} \bar{l}_{e}=\left(1+b_{e}\right) \bar{l}_{e}=\left(1+b_{e}\right) \bar{h} \frac{N_{e}}{Q_{e}},
$$

where $\bar{h}$ is the per-worker worked hours in the economy and the individual time endowment. We can therefore deduce the calibrated value for $b$, since $1=\left(1+b_{e}\right) \frac{N_{e}}{P_{e}}$ and we already know $\frac{Q}{P}$ and $\frac{N}{Q}=1-\frac{Q}{P}$. Concerning the average value of the per-capita quarterly worked hours in the economy $\bar{h}$, we can calculate this by multiplying the average per-worker quarterly worked hours and the employment population, computing the per-capita values dividing by the total labor force. All these data were obtained from the St. Louis Federal Reserve Bank FRED ${ }^{\circledR}$ Database.

The calibration of the remaining parameters $A, a$ and $\delta$ was based on the expressions along the balanced path of growth of the feasibility constraint, the production function and the growth rate. More specifically, these expressions are

$$
\begin{gathered}
C_{e}+h_{e+1}\left(1+\frac{1}{a}\right)\left(1+p_{e}\right)=y_{e}+h_{e}[1-\delta], \\
y_{e}=A h_{e}\left(\bar{h} \frac{Q_{e}}{P_{e}}\right)^{1-\alpha},
\end{gathered}
$$

and

$$
\psi=\left[\frac{\beta\left(A\left(\bar{h} \frac{Q_{e}}{P_{e}}\right)^{1-\alpha}+1-\delta\right)}{\left(1+\frac{1}{a}\right)\left(1+p_{e}\right)}\right]^{\frac{1}{\sigma}}-1
$$

when

$$
U\left(C_{e}\right)=\frac{C_{e}^{1-\sigma}-1}{1-\sigma}, \quad(\sigma>0) \wedge(\sigma \neq 1),
$$

or, alternatively,

$$
\psi_{h}=\left[\frac{\beta\left(A\left(\bar{h} \frac{Q_{e}}{P_{e}}\right)^{1-\alpha}+1-\delta\right)}{\left.1+\frac{1}{a}\right)\left(1+p_{e}\right)}\right]-1
$$

when $U\left(C_{e}\right)=\ln \left(C_{e}\right)$. After substituting $h_{e}=a k_{e}$ and considering the properties of the balanced path of growth, the former equations become

$$
\begin{gathered}
\frac{C}{y}+(1+a)(1+n)(1+\psi) \frac{k}{y}=1+a \frac{k}{y}[1-\delta], \\
1=A a \frac{k}{y}\left(\bar{h} \frac{Q_{e}}{P_{e}}\right)^{1-\alpha},
\end{gathered}
$$

and

$$
\psi=\left[\frac{\beta\left(A\left(\bar{h} \frac{Q_{e}}{P_{e}}\right)^{1-\alpha}+1-\delta\right)}{\left(1+\frac{1}{a}\right)(1+n)}\right]^{\frac{1}{\sigma}}-1
$$


when

$$
U\left(C_{e}\right)=\frac{C_{e}^{1-\sigma}-1}{1-\sigma}, \quad(\sigma>0) \wedge(\sigma \neq 1),
$$

or, alternatively,

$$
\psi_{h}=\left[\frac{\beta\left(A\left(\bar{h} \frac{Q_{e}}{P_{e}}\right)^{1-\alpha}+1-\delta\right)}{\left(1+\frac{1}{a}\right)(1+n)}\right]-1
$$

when $U\left(C_{e}\right)=\ln \left(C_{e}\right)$.

In these equations, the steady values for $\frac{C}{y}, \frac{k}{y}$ and $\psi$ are taken directly from the $\mathrm{FRED}^{\circledR}$ data set as their mean values, the values for $\bar{h}, \frac{Q}{P}, \alpha, \beta$ and $\sigma$ being those previously calibrated. The result is a system of 3 equations and 3 unknowns, namely $A, a$ and $\delta$. By solving this system, the calibrated values for these unknowns are calculated. On this point, it is worth noting that $\delta=\delta_{h}-\frac{1-\delta_{k}}{a}$, and then we must not expect a value $\delta \in(0,1)$. On the contrary, logical values for $\delta_{h}$ and $\delta_{k}$ should imply a calibrated value of $\delta$ negative and close to $-\frac{1}{a}$, as indeed happens.

Finally, to calibrate the standard deviations of the stochastic variables $b_{e}, n_{e}$ and $\frac{Q_{e}}{P_{e}}$, we will fix the values that best reproduce the statistical moments of the observed series for $\psi_{y}$. Note that, given that the data set provides 4 different (although similar) growth rates -namely $\psi_{y}, \psi_{C}, \psi_{k}$ and $\psi_{k / l^{-}}$, this calibration procedure can be run for each case, or even for the average values ${ }^{13}$. In this respect, we have opted to reproduce the statistical moments for $\psi_{y}$. In order to gain insights into the role played by each stochastic variable, three different simulations will be carried out, one for each specific stochastic variable.

Tables 1 and 2 collect, respectively, the growth facts of the US economy for the considered period and the calibrated values. As shown in table 1 , the US economy presents for the period 1964:1-2009:4 all the usual stylized facts concerning growth. All the values in table 1 correspond to the trend obtained after applying the Hodrick-Prescott filter to the original data.

Table 1: Growth facts. US data, 1964:1-2009:4

\begin{tabular}{|c|c|c|}
\hline \hline Parameter & Mean & Coefficient of Variation \\
\hline \hline $\bar{h}$ & 298.5187 & 0.0458 \\
\hline$\frac{C}{y}$ & 0.6385 & 0.0374 \\
\hline$\frac{k}{y}$ & 32.9506 & 0.0426 \\
\hline$\psi_{y}$ & 0.0038 & 0.8615 \\
\hline$\psi_{C}$ & 0.0045 & 0.5705 \\
\hline$\psi_{k}$ & 0.0034 & 0.4158 \\
\hline$\psi_{k / l}$ & 0.0042 & 0.0458 \\
\hline$n$ & 0.0019 & $\mathrm{NA}$ \\
\hline
\end{tabular}

\footnotetext{
${ }^{13}$ This implies recalibrating the parameters $a, A$ and $\delta$ with the value of $\psi$ taken into account.
} 
In particular, the data show that per-capita output, per-capita consumption, per-capita physical capital and physical capital per worker grow at very similar rates, that employment and the consumption/output and physical capital/output ratios are roughly constant, and that the variability of the growth rates for per-capita output, per-capita consumption, and per-capita physical capital are of the same order of magnitude.

\begin{tabular}{|c|c|c|}
\hline Parameter & $U\left(C_{e}\right)=\ln \left(C_{e}\right)$ & $U\left(C_{e}\right)=\frac{C_{e}^{1-\sigma}-1}{1-\sigma}$ \\
\hline$\psi$ & 0.003821 & 0.003821 \\
\hline$\alpha$ & 0.3541 & 0.3541 \\
\hline $\bar{h}$ & 298.5187 & 298.5187 \\
\hline$\frac{Q}{P}$ & 0.08033 & 0.08033 \\
\hline$a$ & 0.914394 & 0.660035 \\
\hline$A$ & 0.00427923 & 0.00592316 \\
\hline$\frac{C}{y}$ & 0.638531 & 0.638531 \\
\hline$\frac{k}{y}$ & 32.95061 & 32.95061 \\
\hline$\beta$ & 0.99 & 0.99 \\
\hline$\sigma$ & - & 1.4 \\
\hline$\delta$ & -1.09357 & -1.5128 \\
\hline$b_{e}$ & $\mathrm{~N}(0.08734655,0.0024)$ & $\mathrm{N}(0.08734655,0.00335)$ \\
\hline$\frac{Q_{e}}{P_{e}}$ & $\mathrm{~N}(0.08033,0.022)$ & $\mathrm{N}(0.08033,0.0261)$ \\
\hline$n_{e}$ & $\mathrm{~N}(0.0019,0.00413)$ & $\mathrm{N}(0.0019,0.00413)$ \\
\hline
\end{tabular}

To simulate the model, according to the calibrated values for each case, we generated a series of 184 values for each considered stochastic perturbation, from which the associated series for $\psi_{t}$ was obtained. After running each simulation 1000 times, the results are those in table 3 . 


\begin{tabular}{|c|c|c|c|c|}
\hline $\begin{array}{l}\text { Stochastic } \\
\text { Variable }\end{array}$ & Moment & Data & $U(C)=\ln (C)$ & $U(C)=\frac{C^{1-\sigma}-1}{1-\sigma}$ \\
\hline \multirow[t]{4}{*}{$b_{e}$} & Mean, $\psi_{y}$ & 0.0038 & 0.0037 & 0.0037 \\
\hline & $\mathrm{CV}, \psi_{y}$ & 0.86 & 0.86 & 0.86 \\
\hline & Mean, $\bar{l}$ & 298.52 & 298.86 & 299.00 \\
\hline & $\mathrm{CV}, \bar{l}$ & 0.0458 & 0.0034 & 0.0048 \\
\hline \multirow[t]{4}{*}{$\frac{Q_{e}}{P_{e}}$} & Mean, $\psi_{y}$ & 0.0038 & 0.0037 & 0.0036 \\
\hline & $\mathrm{CV}, \psi_{y}$ & 0.86 & 0.86 & 0.86 \\
\hline & Mean, $\bar{l}$ & 298.52 & 298.59 & 298.60 \\
\hline & $\mathrm{CV}, \bar{l}$ & 0.0458 & 0.0267 & 0.0316 \\
\hline \multirow[t]{4}{*}{$n_{e}$} & Mean, $\psi_{y}$ & 0.0038 & 0.0038 & 0.0038 \\
\hline & $\mathrm{CV}, \psi_{y}$ & 0.86 & 0.86 & 0.86 \\
\hline & Mean, $\bar{l}$ & 298.53 & 298.53 & 298.53 \\
\hline & $\mathrm{CV}, \bar{l}$ & 0.0458 & 0 & 0 \\
\hline
\end{tabular}

After a first inspection of the simulation results, several conclusions arise. First, there exist no significative differences when opting between the two considered Bernoulli utility functions. Indeed, these differences only appear for the calibrated values, being practically non-existent for the simulation outputs. This fact suggests that the elasticity of intertemporal substitution in consumption is not a key parameter in macroeconomic growth models. From the theoretical point of view this is a logical result, since the intertemporal elasticity of substitution in consumption measures the response of the growth rate of consumption to the real interest rate, and, as shown in section 3 , the real interest rate remains constant in the proposed model as well as in real economies. Second, all the simulations do quite well in replicating the mean and the variation coefficient for both the per-capita GDP growth rate and the per-capita worked hours. Moreover, the simulation exercise when the perturbation affects the ratio of immigrant population is especially good, and it can therefore be concluded that this Romer-AK endogenous growth model, based on the complementarity between native and immigrant labor, satisfactorily explains the observed behavior of the economy concerning growth, at least as well as the existing alternative models. In addition and as we have shown, the proposed model also allows the effects of population and immigration on growth to be evaluated and clarified, thus constituting a good and interesting candidate to take into account when studying these questions. Third, although in our simulations we have isolated the effects of each stochastic perturbation -namely $b_{e}, \frac{Q_{e}}{P_{e}}$ or $n_{e^{-}}$, the consideration of two or more simultaneous shocks is also possible. In this respect, 
since with the only exception of a null coefficient of variation of the per-capita worked hours, the simulation for $n_{e}$ perfectly reproduces the observed data, the joint consideration of $n_{e}$ and $b_{e}$, of $n_{e}$ and $\frac{Q_{e}}{P_{e}}$, or even of the three shocks $b_{e}$, $n_{e}$ and $\frac{Q_{e}}{P_{e}}$, might improve the simulation results. Finally, the introduction of a new technological shock affecting the complementarity between physical and human capital as in Gutiérrez (2015) is also feasible, opening new possibilities of combination. In this respect, it is worth noting that our exercises considering simultaneous perturbations $n_{e}$ and $b_{e}$ and $n_{e}$ and $\frac{Q_{e}}{P_{e}}$ have not implied any gain with respect to the simulations based on the existence of only one shock, probably because of our assumption of independent perturbations. Indeed, the correct introduction of simultaneous perturbations would require the calibration of additional parameters for the stochastic shocks, including those measuring correlations.

\section{Conclusions and future research}

Over the last few decades and as a direct consequence of the concern on growth sustainability, Economics has increased its interest in studying the relationships between growth, population and immigration. At the empirical level and concerning the links between population and growth, the current consensus is that high population growth exerts a negative effect both on GDP growth and human capital accumulation, this effect being negligible when population growth rates take moderate values. Regarding immigration, the main empirical conclusion, based on the observed strong complementarity between native and immigrant workers, is that immigration and growth are linked in a double sense: the growth dynamics of the host economy gives rise to an immigration demand, which, in turn, affects growth through its effects on the human capital accumulation process. At the theoretical level, however, this empirical evidence on the links between population, immigration and growth, has not yet been satisfactorily explained, incorporated or discussed by theoretical models. Indeed, to our knowledge, there is in the literature no referential endogenous growth model detailing how and why economic growth can, or cannot, be negatively dependent on population growth through the process of human capital accumulation, nor analyzing in detail the consequences on growth of the observed complementarity between native and immigrant workers.

In this respect, we have built a model that incorporates the above mentioned facts concerning immigration and population into a pure endogenous growth model à la Romer. In particular, the model's main characteristics are the following: the growth dynamics is explained by the endogenous human capital accumulation process; the demand of immigration endogenously arises as a consequence of the productive needs of the economy; and this immigration subsequently alters growth through modifications in the human capital accumulation. Two are the main virtues of this model. On the one hand, it provides a theoretical endogenous growth model able to capture the links between population, immigration and growth commented on above. On the other hand, the proposed model is susceptible to calibration and simulation, allowing the relationships between population, immigration and growth to be estimated and simulated for different scenarios.

Indeed, from the theoretical perspective and regarding the links between 
population and growth, the model is able to explain the empirically observed negative effect of a high population growth rate on the per capita GDP growth, and does so, as the evidence shows, through the endogenous process of human capital accumulation. In addition, the model also predicts a negligible effect of population growth on economic growth when the growth rates take normal values. Regarding immigration and its effects on economic growth, and on the basis of the assumption of complementarity in production between immigrant and native labor, the model allows several channels of influence to be considered. More specifically, the model contemplates the two-way effects linking growth and immigration, and permits distinct relationships between technological change and immigration to be elucidated. In the light of the implemented simulations all these findings appear as plausible, since the proposed version of Romer's model satisfactorily explains the observed behavior of the economy concerning growth, at least as well as the existing alternative models.

Summing up, the proposed model constitutes a good and interesting candidate to study endogenous growth and its relationships with population and immigration. Indeed, not only does it provide a coherent and consistent theoretical explanation of the links between population growth, immigration and GDP growth, it also allows interesting exercises of calibration and simulation to be implemented, opening up the possibility of using the model to design and evaluate different immigration policies.

In this respect, future research necessarily passes through the solution of two inconveniences of the model, both inherent to its theoretical characteristics. First, since the model generates a common growth rate for all the growing variables -namely per capita consumption, physical capital, and output; and capital/labor ratio-, the application of the model embodies problems when the objective is to replicate the different observed volatilities for the growth rate series. Indeed, although the means of the growth rates for all the considered variables are usually very similar and their replication for the model does not therefore entail problems, the growth rate standard deviations habitually take different values, something that demands the consideration of variablespecific stochastic perturbations. Second, the consideration of simultaneous shocks would require the calibration of additional parameters for the stochastic shocks, including those measuring correlations, since, on the contrary and as shown in our simulation exercises, the obtained results could be misleading.

\section{References}

[1] Accinelli, E. and Carrera, E.J.S. (2012): The Evolutionary Game of Poverty Traps. Manchester School, 80, 4, pp. 381-400.

[2] Acemoglu, D. (2009): Introduction to Modern Economic Growth. Princeton University Press.

[3] Aghion, P. and Howitt, P. (1992): A Model of Growth Through Creative Destruction. Econometrica, 60, pp. 323-351.

[4] Aghion, P. and Howitt, P. (2009): The Economics of Growth. Cambridge MA: MIT Press. 
[5] Alcantar-Toledo, J, and Venieris, Y.P. (2014): Fiscal Policy, Growth, Income Distribution and Sociopolitical Instability. European Journal of Political Economy 34, 0, pp. 315-31.

[6] Altuğ, S. and Labadie, P. (1994): Dynamic Choice and Asset Markets. Academic Press.

[7] Amuedo-Dorantes, C. and De La Rica, S. (2011): Complements or Substitutes? Task Specialization by Gender and Nativity in Spain. Labour Economics, 18, pp. 697707.

[8] Azariadis, C. and Stachurski, J. (2005): Poverty Traps. Chap. 5, Handbook of Economic Growth, Vol. 1, Part A, Philippe Aghion and Steven N. Durlauf (eds), Elsevier.

[9] Barrett, C.B. and Carter, M.R. (2013): The Economics of Poverty Traps and Persistent Poverty: Empirical and Policy Implications. Journal of Development Studies, 49, 7, pp. 976-90.

[10] Barro, R.J. (1990): Government Spending in a Simple Model of Endogenous Growth. Journal of Political Economy, 98, 5, part II, pp. S103-S125.

[11] Barro, R.J. and X. Sala-i-Martin (2003): Economic Growth. McGraw Hill.

[12] Becker, G.S., Murphy, K.M. and Tamura, R. (1990): Human Capital, Fertility, and Economic Growth.. Journal of Political Economy, 98, s12-s37.

[13] Binder, M. and Pesaran, M.H. (1999): Stochastic Growth Models and Their Econometric Implications. Journal of Economic Growth, 4, pp. 139-183.

[14] Bloom, D. and Canning, D. (2001): Cumulative Causality, Economic Growth, and the Demographic Transition. In Population Matters. Demographic Change, Economic Growth, and Poverty in the Developing World, N. Birdsall, A.C. Kelley, and S. Sinding (eds.), Oxford University Press.

[15] Bond, E.W, Iwasa, K. and Nishimura, K. (2013): Poverty Traps and Inferior Goods in a Dynamic Heckscher-Ohlin Model. Macroeconomic Dynamics, 17, 6, pp. 1227-51.

[16] Brito, P.B., Costa, L.F. and Dixon, H. (2013): Non-smooth Dynamics and Multiple Equilibria in a Cournot-Ramsey Model with Endogenous Markups. Journal of Economic Dynamics and Control, 37, 11, pp. 22872306.

[17] Borjas, G.J. (1983): The Substitutability of Black, Hispanic, and White Labor. Economic Inquiry, 21, pp. 93-106.

[18] Borjas, G.J. (1986): The Sensitivity of Labour Demand Functions to Choice of Dependent Variable. Review of Economics and Statistics, 68, pp. 58-66.

[19] Borjas, G.J. (1990): Economic theory and international migration. International Migration Review, 23, pp. 457485.

[20] Borjas, G.J. (1999): The Economics Analysis of Immigration. In Handbook of Labor Economics, O. Ashenfelter and D. Card (eds): North-Holland. 
[21] Camacho, C., Saglam, C. and Turan, A. (2013): Strategic Interaction and Dynamics under Endogenous Time Preference. Journal of Mathematical Economics, 49, 4, pp. 291-301.

[22] Cass, D. (1965): Optimum Growth in an Aggregative Model of Capital Accumulation. Review of Economic Studies, 32, pp. 233-240.

[23] Chen, S-H. and Guo, J-T. (2008): On the Growth and Velocity Effects of Money. Economics Bulletin, 5, pp. 1-7.

[24] Christiano, L.J. and Eichenbaum, M. (1992): Current Real-Business-Cycle Theories and Aggregate Labor-Market Fluctuations. American Economic Review, 82, pp. 402-17.

[25] Cipriani, G.P. (2006): Endogenous fertility, international migration and growth. International Review of Economics 53(1), 49-67.

[26] Cooley, T.F. and Prescott, E.C. (1995): Economic Growth and Business Cycles. Chap. 1, Frontiers of Business Cycle Research, Cooley, T.F. (ed.), Princeton University Press.

[27] D'Amuri, F., Ottaviano, G. and Peri, G. (2010): The Labor Market Impact of Immigration in Western Germany in the 1990's. European Economic Review, 54, pp. 550-570.

[28] Dao, M.Q. (2012): Population and Economic Growth in Developing Countries. International Journal of Academic Research in Business and Social Sciences, 2, pp. 6-17.

[29] Durlauf, S.N., Johnson, P.A. and Temple, J.R.W. (2005): Growth Econometrics. Chap. 8, Handbook of Economic Growth, Vol. 1, Part A, Philippe Aghion and Steven N. Durlauf (eds), Elsevier.

[30] Dustmann, C., Frattini, T. and Glitz, A. (2007): The Impact of Migration: A Review of the Economic Evidence. CReAM Final Report 11/07.

[31] Dustmann, C., Frattini, T. and Preston, I.P. (2012): The Effect of Immigration along the Distribution of Wages. Review of Economic Studies, 80, pp. $145-173$.

[32] Ehrlich, I. and Kim, J. (2015): Immigration, Human Capital Formation and Endogenous Economic Growth. Journal of Human Capital 9(4), 518563.

[33] Evans, D.J. and Sezer, H. (2004): Social Discount Rates for Six Major Countries. Applied Economics Letters, 11, pp. 557560.

[34] Galor, O. and Weil, D.N.( 2000): Population, Technology, and Growth: Form Malthusian Stagnation to the Demographic Transition and beyond. American Economic Review, 90, pp. 806-828.

[35] Galvao Jr., A.F., Montes-Rojas, G. and Olmo, J. (2013): A Panel Data Test for Poverty Traps. Applied Economics, 45, 13-15, pp. 1943-1952.

[36] Goodfriend, M. and McDermott, J. (1995): Early Development. American Economic Review, 85, pp. 116-133. 
[37] Grossman, G.M. and Helpman, H. (1991): Innovation and Growth in the Global Economy. Cambridge, MA: MIT Press.

[38] Gutiérrez, P.J. (2002): Producción e Incertidumbre en Equilibrio General Dinámico. Septem Ediciones.

[39] Gutiérrez, P.J. (2015): A Full Test of a Romer's Endogenous Growth Model. International Journal of Economics and Business Research 10, pp. 297-325.

[40] Hansen, G.D. and Prescott, E.C. (2002): Malthus to Solow. American Economic Review, 92, pp. 1205-1217.

[41] Higgings, M and Williamson, J.G. (1997): Age Structure Dynamics in Asia and Dependence of Foreign capital. Population and Development Review, 23, pp. 261-293.

[42] Howitt, P. (1999): Steady Endogenous Growth with Population and R\&D Inputs Growing. Journal of Political Economy, 107, pp. 715-730.

[43] Jones, L. and Manuelli, R.E. (1990): A Convex Model of Equilibrium Growth: Theory and Policy Implications. Journal of Political Economy, 98, pp. 1008-1038.

[44] Kaldor, N. (1957): A Model of Economic Growth. Economic Journal, 67, pp. 591-624.

[45] Kelley, A.C. and Schmidt, R.M. (2003): Economic and Demographic Change: A Synthesis of Models, Findings, and Perspectives. In Population Matters. Demographic Change, Economic Growth, and Poverty in the Developing World, N. Birdsall, A.C. Kelley, and S. Sinding (eds.), Oxford University Press.

[46] Kim, J.U. (2003): Economic Growth and Returns to Scale for Reproductible Factors. Applied Economics Letters, 10, pp. 925-928.

[47] Kónya, L. (2009): Immigration, Economic Growth and Unemployment in Australia, 1972-2007. Global Business and Economics Review, 11, pp. 288303.

[48] Kraay, A. and McKenzie, D. (2014): Do Poverty Traps Exist? Assessing the Evidence. Journal of Economic Perspectives, 28, 3, pp. 127148.

[49] Krawczyk, J.B. and Shimomura,K. (2003): Why Countries with the Same Technology and Preferences Can Have Different Growth Rates? Journal of Economic Dynamics and Control, 27, pp. 1899-1916.

[50] Li, D. (2002): Is the AK Model still Alive? The Long-Run Relation between Growth and Investment Re-examined. Canadian Journal of Economics, 35, pp. 92-114.

[51] Lucas, R.E., Jr. (1988): On the Mechanics of Economic Development. Journal of Monetary Economics, 22, 1, pp. 3-42. 
[52] Lucas, R.E., Jr. (2009): Trade and the Diffusion of the Industrial Revolution. American Economic Journal: Macroeconomics, 1, pp.1-25.

[53] Malthus, T. R. (1826): An Essay on the Principle of Population. 6th. Ed., London: John Murray.

[54] Manacorda, M., Manning, A. and Wadsworth, J. (2012): The Impact of Immigration on the Structure of Male Wages: Theory and Evidence from Britain. Journal of the European Economic Association, 10, pp. 120-151.

[55] Mason, A. (1997): Population and the Asian Economic Miracle. AsiaPacific Population and Policy, 43.

[56] McGrattn, E.R. (1998): A Defence of AK Growth Models. Federal Reserve Bank of Minneapolis Quarterly Review, 22, pp. 13-27.

[57] Milewski, N. (2007): First Child of Immigrant Workers and Their Descendents in West Germany: Interrelation of Events, Disruption, or Adaptation? Demographic Research, 17, pp. 859-896.

[58] Moav, O. and Neeman, Z. (2012): Saving Rates and Poverty: The Role of Conspicuous Consumption and Human Capital. Economic Journal, 122, 563 , pp. 933-56.

[59] Nelson, R.R. (1956): A Theory of the Low-Level Equilibrium Trap in Underdeveloped Economies. American Economic Review 46, 5, pp. 894908.

[60] Ottaviano, G. and Peri, G. (2012): Rethinking the Effects of Immigration on Wages. Journal of the European Economic Association, 10, pp. 152-197.

[61] Peri, G. (2007): Immigrants' Complementarities and Native Wages: Evidence from California. NBER WP 12956.

[62] Poot, J. and Cochrane, B. (2005): Measuring the Economic Impact of Immigration: A Scoping Paper. Population Studies Centre, Discussion Paper no. 48.

[63] Public Policy Institute of California (2002): How Fertility Changes across Immigrant Generations. Research Brief, April.

[64] Raffin, N. (2012): Children's Environmental Health, Education, and Economic Development. Canadian Journal of Economics, 45, 3, pp. 996-1022.

[65] Rebelo, S. (1991) Long-Run Policy Analysis and Long-Run Growth. Journal of Political Economy, 99, 3, pp. 500-521.

[66] Rey, S. and Deisting, F. (2012): GDP Per Capita among African Countries over the Period 1950-2008: Highlights of Convergence Clubs. Economics Bulletin, 32, 4, pp. 2779-2800.

[67] Romer, P.M. (1986): Increasing Returns and Long-Run Growth. Journal of Political Economy, 94, 5, pp. 1002-1036.

[68] Romer, P.M. (1990): Endogenous Technological Change. Journal of Political Economy, 98, pp. S71-S102. 
[69] Romero-Ávila, D. (2009): Productive Physical Investment and Growth: Testing the Validity of the AK Model from a Panel Perspective. Applied Economics, 41, pp. 3027-3043.

[70] Romero-Ávila, D. (2013): Is Physical Investment the Key to China's Growth Miracle? Economic Inquiry, 51, pp. 1948-1971.

[71] Rubinstein, M. (1974): An Aggregation Theorem for Securities Markets. Journal of Financial Economics, 1, pp. 225-244.

[72] Sachs, J. (2008): Common Wealth: Economics for a Crowded Planet. London: Penguin Press.

[73] Sattinger, M. (2013): Safety First Consumption. Journal of Economic Theory, 148, 1, pp. 306-21.

[74] Sobotka, T. (2008): The Rising Importance of Migrants for Childbearing in Europe. Demographic Research, 19, pp. 225-248.

[75] Tønnessen, M. (2014): Fertility Rates and Other Demographics among Immigrants and Children of Immigrants Born in Norway. Statistics Norway, January.

[76] Weber, L. (2010): Demographic Growth Model. In Demographic Change and Economic Growth. Simulations on Growth Models. Physica-Verlag, Springer.

[77] Yamarik, S. (2001): Nonlinear Tax Structures and Endogenous Growth. The Manchester School, 69, pp. 16-30.

[78] Young, A. (1998): Growth without Scale Effects. Journal of Political Economy, 106, pp. 41-63.

[79] Zak, P., Feng,Y. and Kugler, J. (2002): Immigration, Fertility and Growth. Journal of Economic Dynamics and Control, 26, 547-576.

\section{A Social Planner's Problem}

We will follow analogous arguments to those in Gutiérrez (2015) to obtain the social planner's problem formulation. Let us assume without any loss of generality that the total number of firms is $J=2$. When the Government internalizes the external economies associated to knowledge through optimal taxes and subsidies, each firm's problem is

$$
\begin{gathered}
\max _{K_{e}^{i}, L_{e}^{i}, H_{e}^{i}, M_{e}^{i}, h_{e}^{j}} P R_{e}^{i}=A\left[\min \left\{a_{e} K_{e}^{i}, H_{e}^{i}\right\}\right]^{\alpha}\left[\min \left\{b_{e} L_{e}^{i}, M_{e}^{i}\right\}\right]^{1-\alpha}\left(\prod_{j \neq i} h_{e}^{j}\right)^{\rho}- \\
w_{e} L_{e}^{i}-g_{e} M_{e}^{i}-r_{e} K_{e}^{i}-d_{e} H_{e}^{i}+S_{e} H_{e}^{i}-S_{e} P_{e} h_{e}^{j}+P_{e} V_{e}^{i}, \\
i, j=1,2, \quad i \neq j,
\end{gathered}
$$

where $P R$ denotes profits, $S$ is the subsidy/tax to knowledge input, $P$ is the total number of households, and $V$ is a per-capita lump-sum subsidy to profits: Note that since $h_{e}^{j}$ and $V_{e}^{i}$ are given in per-capita terms, the total amount of 
human capital of firm $j$ used by firm $i$ and the total subsidy to firm $i$ 's profits are, respectively, $P_{e} h_{e}^{j}$ and $P_{e} V_{e}^{i}$.

Dividing by the total number of households $P_{e}$, the above firm $i$ 's problem can be expressed in per capita terms. Let $p r^{i}, k^{i}, l^{i}, m^{i}$ and $h^{i}$ be firm $i$ 's percapita profits, use of physical capital, labor services of native and immigrant workers (respectively), and human capital. The firm $i$ 's problem is therefore

$$
\begin{gathered}
\max _{k_{e}^{i}, l_{e}^{i}, m_{e}^{i}, h_{e}^{i}, h_{e}^{j}} p r_{e}^{i}=A\left[\min \left\{a_{e} k_{e}^{i}, h_{e}^{i}\right\}\right]^{\alpha}\left[\min \left\{b_{e} l_{e}^{i}, m_{e}^{i}\right\}\right]^{1-\alpha}\left(\prod_{j \neq i} h_{e}^{j}\right)^{\rho}- \\
w_{e} l_{e}^{i}-g_{e} m_{e}^{i}-r_{e} k_{e}^{i}-d_{e} h_{e}^{i}+S_{e} h_{e}^{i}-S_{e} h_{e}^{j}+V_{e}^{i} \\
i, j=1,2, \quad i \neq j .
\end{gathered}
$$

Firms are profit-maximizing, and given the perfect complementarity between physical capital and knowledge and between native and immigrant labor, $a_{e} k_{e}^{i}=$ $h_{e}^{i}$, and $b_{e} l_{e}^{i}=m_{e}^{i}$. Then the firm's problem becomes

$$
\begin{gathered}
\max _{m_{e}^{i}, h_{e}^{i}, h_{e}^{j}} p r_{e}^{i}=A\left(h_{e}^{i}\right)^{\alpha}\left(m_{e}^{i}\right)^{1-\alpha}\left(h_{e}^{j}\right)^{\rho}- \\
-\left(\frac{w_{e}}{b_{e}}+g_{e}\right) m_{e}^{i}-h_{e}^{i}\left(m_{e}+\frac{r_{e}}{a_{e}}-S_{e}\right)-S_{e} h_{e}^{j}+V_{e}^{i}, \\
i, j=1,2, \quad i \neq j .
\end{gathered}
$$

The first order necessary and sufficient conditions are

$$
\begin{gathered}
A \alpha\left(h_{e}^{i}\right)^{\alpha-1}\left(h_{e}^{j}\right)^{\rho}\left(m_{e}^{i}\right)^{1-\alpha}=\frac{r_{e}}{a_{e}}+d_{e}-S_{e}, \\
A \rho\left(h_{e}^{i}\right)^{\alpha}\left(h_{e}^{j}\right)^{\rho-1}\left(m_{e}^{i}\right)^{1-\alpha}=S_{e} \\
A(1-\alpha)\left(h_{e}^{i}\right)^{\alpha}\left(h_{e}^{j}\right)^{\rho}\left(m_{e}^{i}\right)^{-\alpha}=\frac{w_{e}}{b_{e}}+g_{e}, \\
i, j=1,2, \quad i \neq j .
\end{gathered}
$$

It is clear that $m_{e}^{1}=m_{e}^{2}=l_{e}$ and $h_{e}^{1}=h_{e}^{2}=h_{e}$, and then the former equations can be written as

$$
\begin{gathered}
A(\alpha+\rho) h_{e}^{\alpha+\rho-1} l_{e}^{1-\alpha}=\frac{r_{e}}{a_{e}}+d_{e} \\
A(1-\alpha) h_{e}^{\alpha+\rho} l_{e}^{-\alpha}=\frac{w_{e}}{b_{e}}+g_{e}
\end{gathered}
$$

which are the first order necessary and sufficient conditions for the problem

$$
\max _{h_{e}, m_{e}} p r_{e}=A h_{e}^{\alpha+\rho} m_{e}^{1-\alpha}-\left(\frac{w_{e}}{b_{e}}+g_{e}\right) m_{e}-h_{e}\left(\frac{r_{e}}{a_{e}}+d_{e}\right)+V_{e} .
$$

Each firm's profits in per-capita terms are therefore

$$
p r_{e}=-A \rho h_{e}^{\alpha+\rho} m_{e}^{1-\alpha}+V_{e},
$$

which depend on the government lump-sum subsidy to profits. When $V_{e}=$ $A \rho h_{e}^{\alpha+\rho} m_{e}^{1-\alpha}$, then $p r_{e}=0$, and the production sector is in a long-run equilibrium.

We can now define the general equilibrium of this economy as follows: 
Definition (Long-Run Competitive General Equilibrium). Sequences $\left\{C_{e}^{n}\right\}$, $\left\{C_{e}^{q}\right\},\left\{h_{e}^{n}\right\},\left\{h_{e}^{q}\right\},\left\{k_{e}^{n}\right\},\left\{k_{e}^{q}\right\},\left\{l_{e}^{n}\right\},\left\{m_{e}^{q}\right\},\left\{h_{e}\right\},\left\{k_{e}\right\},\left\{l_{e}\right\},\left\{m_{e}\right\},\left\{w_{e}\right\},\left\{g_{e}\right\}$, $\left\{r_{e}\right\},\left\{d_{e}\right\},\left\{T_{e}^{n}\right\},\left\{T_{e}^{q}\right\}$ and $\left\{P_{e}\right\}$ such that:

- Given the sequences $\left\{w_{e}\right\},\left\{r_{e}\right\},\left\{d_{e}\right\}$ and $\left\{T_{e}^{n}\right\}$, the sequences $\left\{C_{e}^{n}\right\}$, $\left\{h_{e}^{n}\right\},\left\{k_{e}^{n}\right\}$ and $\left\{l_{e}^{n}\right\}$ solve the representative consumer's problem for the native workers (1).

- Given the sequences $\left\{g_{e}\right\},\left\{r_{e}\right\},\left\{d_{e}\right\}$ and $\left\{T_{e}^{q}\right\}$, the sequences $\left\{C_{e}^{q}\right\},\left\{h_{e}^{q}\right\}$, $\left\{k_{e}^{q}\right\}$ and $\left\{m_{e}^{q}\right\}$ solve the representative consumer's problem for the immigrant workers (2).

- Given the sequences $\left\{w_{e}\right\},\left\{g_{e}\right\},\left\{r_{e}\right\},\left\{d_{e}\right\}$ and $\left\{V_{e}\right\}$, the sequences $\left\{h_{e}\right\}$, $\left\{k_{e}\right\},\left\{l_{e}\right\}$ and $\left\{m_{e}\right\}$ solve the representative firm's problem (9) and verify $a_{e} k_{e}=h_{e}$ and $b_{e} l_{e}=m_{e}$.

- The sequences $\left\{C_{e}^{n}\right\},\left\{C_{e}^{q}\right\},\left\{h_{e}^{n}\right\},\left\{h_{e}^{q}\right\},\left\{k_{e}^{n}\right\},\left\{k_{e}^{q}\right\},\left\{l_{e}^{n}\right\},\left\{m_{e}^{q}\right\},\left\{h_{e}\right\}$, $\left\{k_{e}\right\},\left\{l_{e}\right\}$ and $\left\{m_{e}\right\}$ verify the market clearing conditions

$$
\begin{gathered}
k_{e}^{n}+k_{e}^{q}=k_{e}, \quad h_{e}^{n}+h_{e}^{q}=h_{e}, \quad l_{e}^{n}=l_{e}, \quad m_{e}^{q}=m_{e}, \\
C_{e}^{n}+C_{e}^{q}+k_{e+1}\left(1+p_{e}\right)+h_{e+1}\left(1+p_{e}\right) \leq \\
\leq A h_{e}^{\alpha+\rho} m_{e}^{1-\alpha}+k_{e}\left(1-\delta_{K}\right)+h_{e}\left(1-\delta_{h}\right) .
\end{gathered}
$$

- Government sequences of lump-sum taxes $\left\{T_{e}^{n}\right\}$ and $\left\{T_{e}^{q}\right\}$, and subsidies $\left\{V_{e}\right\}$, verify

$$
T_{e}^{n}+T_{e}^{q}=V_{e}=A \rho h_{e}^{\alpha+\rho}\left(m_{e}\right)^{1-\alpha} .
$$

Under quite general conditions, this formulation of Romer's (1986) model as a long-run competitive general equilibrium is equivalent to a very simple social planner's problem. Assuming appropriate homogeneity conditions in beliefs and preferences for native and immigrant workers ${ }^{14}$, and following similar arguments to those in Rubinstein (1974), Altuğ and Labadie (1994) and Gutiérrez (2002), we can ensure that the consumer's problems for native and immigrant workers (1) and (2) are, for a wide range of formulations, equivalent to the following unique per-capita problem:

$$
\begin{gathered}
\max _{C_{e}^{R}, k_{e}^{R}, h_{e}^{R}, l_{e}^{R}, m_{e}^{R}} \sum_{e \in \mathcal{E}} \beta^{t(e)} \pi(e) U\left(C_{e}^{R}\right) \\
\text { s.t. } \quad C_{e}^{R}+\left[k_{e+1}^{R}\left(1+p_{e}\right)-k_{e}^{R}\left(1-\delta_{k}\right)\right]+\left[h_{e+1}^{R}\left(1+p_{e}\right)-h_{e}^{R}\left(1-\delta_{h}\right)\right]+T_{e}^{R} \leq \\
w_{e} l_{e}^{R}+g_{e} m_{e}^{R}+r_{e} k_{e}^{R}+d_{e} h_{e}^{R}, \\
C_{e}^{R} \geq 0, \\
0 \leq l_{e}^{R} \leq \bar{l}_{e}, \quad m_{e}^{R} \leq \bar{m}_{e}, \\
e \in \mathcal{E} \\
k_{0}^{R}, h_{0}^{R} \quad \text { historically given, }
\end{gathered}
$$

where: $\beta, \pi$ and $U$ capture the average discount factor, beliefs and instantaneous utility for the native and immigrant workers; and $C^{R}=C^{n}+C^{q}, k^{R}=k^{n}+k^{q}$,

\footnotetext{
${ }^{14}$ In general, it is enough to assume hyperbolic absolute risk aversion preferences.
} 
$h^{R}=h^{n}+h^{q}, T^{R}=T^{n}+T^{q}, m^{R}=m^{q}$, and $l^{R}=l^{n}$, are, respectively, the economy per capita consumption of good, participation in physical capital, level of knowledge, taxes paid to government, labor supply of immigrant workers, and labor supply of native workers.

Removing the superscripts, from the first order necessary conditions in the firm's problem, the perfect complementarity between physical capital and knowledge and between native and immigrant labor, the market clearing conditions and the equality $T_{e}=V_{e}=\rho h_{e}^{\alpha+\rho}\left(m_{e}\right)^{1-\alpha}$, the representative household's budget constraint becomes

$$
C_{e}+h_{e+1}\left(1+p_{e}\right)\left(1+\frac{1}{a_{e}}\right) \leq A h_{e}^{\alpha+\rho} m_{e}^{1-\alpha}+h_{e}\left[1-\delta_{h}+\frac{1}{a_{e}}\left(1-\delta_{k}\right)\right],
$$

The long-run competitive general equilibrium is therefore equivalent to the following social planner's problem:

Definition (Equivalent Social Planner's Problem). The equilibrium sequences $\left\{C_{e}\right\},\left\{h_{e}\right\}$ and $\left\{m_{e}\right\}$ in the Long-Run Competitive General Equilibrium are given by the solution of the social planner's problem

$$
\max _{C_{e}, h_{e}, m_{e}} \sum_{e \in \mathcal{E}} \beta^{t(e)} \pi(e) U\left(C_{e}\right)
$$

s.t. $C_{e}+h_{e+1}\left(1+p_{e}\right)\left(1+\frac{1}{a_{e}}\right) \leq A h_{e}^{\alpha+\rho} m_{e}^{1-\alpha}+h_{e}\left[1-\delta_{h}+\frac{1}{a_{e}}\left(1-\delta_{k}\right)\right]$,

$$
C_{e} \geq 0
$$$$
0 \leq m_{e} \leq \bar{m}_{e},
$$$$
e \in \mathcal{E}
$$

$h_{0} \quad$ historically given.

Alternatively, since $b_{e} l_{e}=m_{e}$, the former social planner's problem can be formulated as follows:

Definition (Equivalent Social Planner's Problem). The equilibrium sequences $\left\{C_{e}\right\},\left\{h_{e}\right\}$ and $\left\{l_{e}\right\}$ in the Long-Run Competitive General Equilibrium are given by the solution of the social planner's problem

$$
\begin{gathered}
\max _{C_{e}, h_{e}, l_{e}} \sum_{e \in \mathcal{E}} \beta^{t(e)} \pi(e) U\left(C_{e}\right) \\
\text { s.t. } C_{e}+h_{e+1}\left(1+p_{e}\right)\left(1+\frac{1}{a_{e}}\right) \leq \\
C_{e} \geq 0, \\
0 \leq l_{e}^{\alpha+\rho}\left(b_{e} l_{e}\right)^{1-\alpha}+h_{e}\left[1-\delta_{h}+\frac{1}{a_{e}}\left(1-\delta_{k}\right)\right], \\
e \in \mathcal{E},
\end{gathered}
$$

$h_{0}$ historically given. 


\section{B Model Dynamics}

Let $\bar{h}$ denote the individual endowment of time, equal for immigrants and natives. Since $\bar{l}_{e}$ and $\bar{m}_{e}$ are the global per-capita time endowments for native and immigrant workers, respectively,

$$
\bar{l}_{e}=\frac{\bar{h} N_{e}}{P_{e}}, \quad \bar{m}_{e}=\frac{\bar{h} Q_{e}}{P_{e}} .
$$

In the long-run competitive general equilibrium of the economy, the immigration policy always ensures $b_{e} \bar{l}_{e}=\bar{m}_{e}$, i.e., always allows the number of immigrants $Q_{e}$ to adjust to the number of native workers in order to fulfill the productive requirements of perfect complementarity between native and immigrant labor inputs. Then, in the long-run competitive general equilibrium,

$$
\begin{gathered}
b_{e} \bar{l}_{e}=\frac{\bar{h} b_{e} N_{e}}{P_{e}}=\frac{\bar{h} Q_{e}}{P_{e}}=\bar{m}_{e}, \\
b_{e} N_{e}=Q_{e}, \quad \ln \left(b_{e}\right)+\ln \left(N_{e}\right)=\ln \left(Q_{e}\right), \\
\dot{Q}_{e}=\dot{b}_{e}+\dot{N}_{e} .
\end{gathered}
$$

Equation (10) simply says that the optimal immigrant population depends on demographic and technological aspects as well as on the immigration policy. This is because $\dot{N}_{e}$ is the natural native population growth rate, but $\dot{Q}_{e}$ is the addition of the natural immigrant population growth rate plus the (positive or negative) modification in the number of immigrants caused by the immigration policy, which must ensure the fulfillment of the perfect complementarity for any value of the technological parameter $b_{e}$. Let us denote the natural population growth rates of natives and immigrants by $n_{e}$ and $q_{e}$, respectively, and by $D_{e}$ the number of admitted (if positive) or repatriated (if negative) immigrants. Since

$$
\dot{Q}_{e}=\dot{b}_{e}+\dot{N}_{e}, \quad \dot{N}_{e}=n_{e}, \quad \dot{Q}_{e}=q_{e}+\frac{D_{e}}{Q_{e}},
$$

the optimal immigration policy requires

$$
q_{e}+\frac{D_{e}}{Q_{e}}=\dot{b}_{e}+n_{e}, \quad \frac{D_{e}}{Q_{e}}=n_{e}+\dot{b}_{e}-q_{e},
$$

and therefore

$$
\begin{gathered}
P_{e+1}=Q_{e+1}+N_{e+1}=Q_{e}\left(1+q_{e}\right)+D_{e}+N_{e}\left(1+n_{e}\right)= \\
Q_{e}\left(1+q_{e}\right)+Q_{e}\left(n_{e}+\dot{b}_{e}-q_{e}\right)+N_{e}\left(1+n_{e}\right)=\left(Q_{e}+N_{e}\right)\left(1+n_{e}\right)+Q_{e} \dot{b}_{e}= \\
P_{e}\left(1+n_{e}\right)+Q_{e} \dot{b}_{e}=P_{e}\left(1+p_{e}\right),
\end{gathered}
$$

and therefore

$$
p_{e}=n_{e}+\frac{Q_{e}}{P_{e}} \dot{b}_{e}=n_{e}+\frac{Q_{e}}{P_{e}}\left(\frac{b_{e}-b_{e-1}}{b_{e-1}}\right) .
$$

Analogously, after some algebra, we can conclude

$$
\left(\frac{\dot{Q}_{e}}{P_{e}}\right)=\frac{\frac{Q_{e+1}}{P_{e+1}}-\frac{Q_{e}}{P_{e}}}{\frac{Q_{e}}{P_{e}}}=\frac{\left(\frac{b_{e}-b_{e-1}}{b_{e}-1}\right)\left(1-\frac{Q_{e}}{P_{e}}\right)}{1+p_{e}},
$$




$$
\frac{Q_{e+1}}{P_{e+1}}=\frac{Q_{e}}{P_{e}}+\frac{Q_{e}}{P_{e}}\left[\frac{\left(\frac{b_{e}-b_{e-1}}{b_{e-1}}\right)\left(1-\frac{Q_{e}}{P_{e}}\right)}{1+p_{e}}\right] .
$$

Therefore, the growth rate dynamics is that defined by the system of equations

$$
\left\{\begin{array}{l}
p_{e}=n_{e}+\frac{Q_{e}}{P_{e}}\left(\frac{b_{e}-b_{e-1}}{b_{e}-1}\right) \\
\frac{Q_{e+1}}{P_{e+1}}=\frac{Q_{e}}{P_{e}}+\frac{Q_{e}}{P_{e}}\left[\frac{\left(\frac{\left(b_{e}-b_{e-1}\right.}{P_{e}-1}\right)\left(1-\frac{Q_{e}}{P_{e}}\right)}{1+p_{e}}\right] \\
\psi_{e}=\left[\frac{\beta\left[A\left(\frac{\bar{h} Q_{e}}{P_{e}}\right)^{1-\alpha}+1-\delta\right]}{\left(1+\frac{1}{a_{e}}\right)\left(1+p_{e}\right)}\right]-1 \\
\psi_{e}=\left[\frac{\beta\left[A\left(\frac{\bar{h} Q_{e}}{P_{e}}\right)^{1-\alpha}+1-\delta\right]}{\left(1+\frac{1}{a_{e}}\right)\left(1+p_{e}\right)}\right]^{\frac{1}{\sigma}}-1
\end{array}\right.
$$

when $U\left(C_{e}\right)=\ln \left(C_{e}\right)$ and $U\left(C_{e}\right)=\frac{C_{e}^{1-\sigma}-1}{1-\sigma}$ (equation (8) or $\left(8^{\prime}\right)$, respectively).

As shown above, system of equations (6)-(8)( $\left.8^{\prime}\right)$ describes the dynamics of the model. In this respect, since $b_{e}$ is a stochastic variable, the evolution of the per-capita GDP growth rate under the optimal immigration policy is complex. To illustrate this fact, it is enough to describe its behavior for a once-for-all change in $b_{e}$. For instance, when $U\left(C_{e}\right)=\ln \left(C_{e}\right)$, if we assume that $b_{e}$ increases (i.e. that $b_{e}-b_{e-1}>0$ ), the immediate effect on $\psi_{e}$ is a decrease that takes place through the increment of $p_{e}$ :

$$
\frac{\partial \psi_{e}}{\partial\left(b_{e}-b_{e-1}\right)}=\frac{\partial \psi_{e}}{\partial p_{e}} \frac{\partial p_{e}}{\partial\left(b_{e}-b_{e-1}\right)}=-\frac{\psi_{e}}{\left(1+p_{e}\right)} \frac{Q_{e}}{P_{e}}<0 .
$$

However, after this immediate decrease, the per-capita GDP growth rate permanently increases as a consequence of the higher ratio $\frac{Q_{e+1}}{P_{e+1}}$, since

$$
\frac{\partial \frac{Q_{e+1}}{P_{e+1}}}{\partial\left(b_{e}-b_{e-1}\right)}=\frac{\frac{Q_{e}}{P_{e}}\left(1-\frac{Q_{e+1}}{P_{e+1}}\right)\left(1+n_{e}\right)}{\left(\frac{Q_{e}}{P_{e}}\left(b_{e}-b_{e-1}\right)+1+n_{e}\right)^{2}}>0
$$

and

$$
\frac{\partial \psi_{e+1}}{\partial \frac{Q_{e+1}}{P_{e+1}}}=\frac{\beta A \alpha \bar{h}^{\alpha}\left(\frac{Q_{e+1}}{P_{e+1}}\right)^{\alpha-1}}{\left(1+\frac{1}{a_{e}}\right)\left(1+p_{e}\right)}>0,
$$

and there are no more changes in $p_{e}$ nor in $\frac{Q_{e}}{P_{e}}$. As is obvious, when modifications in $b_{e}$ happen at every node, the dynamics of $\psi_{e}$ becomes complex, given that it depends on the relative sizes of the simultaneous effects of $b_{e+1}-b_{e}$ and $\frac{Q_{e+1}}{P_{e+1}}$, this last being a consequence of the previous change $b_{e}-b_{e-1}$. 